\title{
Development of Thermo Mechanical Model for Prediction of Temperature Diffusion In Different Fsw Tool Pin Geometries During Joining of Az80A Mg Alloys
}

\section{Dhanesh Babu S D}

Department of Mechanical Engg, St.Joseph College of Engineering

Sevvel P ( $\sim$ sevvel_ready@yahoo.co.in )

S.A. Engineering College https://orcid.org/0000-0003-4557-6444

\section{Senthil Kumar $\mathbf{R}$}

Anna University

\section{Vijayan V}

K.Ramakrishnan College of Technology

\section{Subramani J}

K.Ramakrishnan College of Technology

\section{Original Research Full Papers}

Keywords: Friction Stir Welding, Peak Temperature, Thermo Mechanical Model, Pin Geometry, Grain Size, AZ80A Mg Alloy

Posted Date: February 3rd, 2021

DOI: https://doi.org/10.21203/rs.3.rs-189893/v1

License: (c) (i) This work is licensed under a Creative Commons Attribution 4.0 International License. Read Full License

Version of Record: A version of this preprint was published at Journal of Inorganic and Organometallic Polymers and Materials on February 18th, 2021. See the published version at https://doi.org/10.1007/s10904-021-01931-4. 


\title{
DEVELOPMENT OF THERMO MECHANICAL MODEL FOR PREDICTION OF TEMPERATURE DIFFUSION IN DIFFERENT FSW TOOL PIN GEOMETRIES DURING JOINING OF AZ80A MG ALLOYS
}

Dhanesh Babu S D ${ }^{1}$, Sevvel $\mathrm{P}^{2}$, Senthil Kumar R ${ }^{3}$, Vijayan $\mathrm{V}^{4}$ and Subramani J

${ }^{1}$ Department of Mechanical Engg, St.Joseph College of Engineering, Sriperumbudur,Chennai, Tamilnadu, India

2 \& 5 Department of Mechanical Engg, S.A. Engineering College, Chennai, Tamilnadu, India.

${ }^{3}$ Department of Mechanical Engg, Anna University, Chennai, Tamilnadu, India.

${ }^{4}$ Department of Mechanical Engineering, K.Ramakrishnan College of Technology, Samayapuram, Trichy - 621 112, Tamilnadu, India.

\author{
E-mail : ${ }^{1}$ dhanesh1986mech@gmail.com; ${ }^{2}$ drsevvel@saec.ac.in; \\ ${ }^{3}$ quantum.engg@gmail.com; ${ }^{4}$ vijayan.me@gmail.com; ${ }^{5}$ subramani@ saec.ac.in
}

\begin{abstract}
Heat generated during the friction stir welding (FSW) process is of complex nature and plays a vital role in influencing the quality of the fabricated joints. In this experimental research, an thermo mechanical process model was formulated to estimate the values of peak temperatures generated during the employment of FSW tools with four different pin geometries (namely cylindrical, taper cylindrical, square and triangle) for joining of AZ80A Mg alloy flat plates, to understand their significant role in influencing the size of the grains, their mechanical strength and in the quality of the joints. The peak temperature values of the formulated thermo mechanical process model are found to be consistent with that of the actual experimental results and exhibited relatively very small variation It was observed that the joints fabricated by taper cylindrical pin geometry was found to possess very fine sized grains, due to the generation of ideal peak temperature (ie., $348^{0} \mathrm{C}$ which is nearly $81-82 \%$ of the melting temperature of AZ80A Workpiece).
\end{abstract}


Keywords: Friction Stir Welding, Peak Temperature, Thermo Mechanical Model, Pin Geometry, Grain Size, AZ80A Mg Alloy

\section{INTRODUCTION}

In the recent years, alloys of Magnesium $(\mathrm{Mg})$ are continuously earning great attraction and significance under the category of easy to machine metals together with exceptional strength to weight ratio, for various sectors including automotive, aerospace and structural applications. In addition to these applications, AZ80A Mg alloys are also preferred over polymer \& composite materials in electronic sectors, due to their unique electromagnetic intervention shielding \& heat conduction properties $[1-3]$. At the same time, the HCP (hexagonally close packed) feature \& larger thermal conductivity of this AZ80A $\mathrm{Mg}$ alloys hinders their fabrication by various conventional joining techniques and employment of fusion joining methodologies are found to generate joints with coarse microstructures, severe fracture, porosity, high residual stresses etc [4,

5]. Hence, there exists a need for identifying a reliable and optimal joining technique to obtain unique \& quality AZ80A joints with mechanical preponderance $[6,7]$

Categorized under joining techniques of solid state, friction stir welding (FSW) has been found to be most effective in generating sound quality weldments with equiaxed and fine sized grains. Joints of some series of alloy of $\mathrm{Mg}$ including AZ31B, AZ91C etc have been reported to be successfully obtained by employing this solid state technique of joining namely, FSW in which the frictional heat gets produced because of the continuous rotation of the shoulder of non-expendable FSW tool over the connecting regions of the work piece surfaces to be joined [8 - 10].

The tool employed for carrying out FSW comprises of a unique shoulder and a pin with a particular geometry, which will be employed to obtain joints of the two flat metal plates. This tool will be made to rotate at high speed and then it will be forced to infiltrate into the connecting regions of the joining region of the two workpieces, until the shoulder of tool contacts top surface 
of these flat metal plates. Then, this tool is made to travel along the line of joint. The face of the workpiece, where rotation of tool harmonizes with the direction of joining is indicated as the AS (advancing side) and other face of the workpiece is indicated as RS [11,12].

The frictional heat generated by virtue of the contact betwixt the shoulder of employed tool and the surface of flat metal plates softens their material and plastic deformation of the plasticized material occurs, without melting the metal plates [13]. The softened \& plasticized materials on both sides of the workpieces are stirred around the region of the FSW tool pin (with unique geometrical shape), by the impact of the rotational and translational movements of pin of the tool, which happens along the entire line of travel of the tool pin [14]. Once the pin of the FSW tool is retrieved from the surfaces of the flat metal plates, the plasticized material flows across the metal plates stops, then the cooling of the plasticized material takes place and the welding gets completed successfully [15-17].

Thus, it can be understood that, the technique of FSW joins materials in their solid state itself and due to this reason, it has various added merits like less input of energy, reduced volume of residual stresses, greater strength of weld etc when compared to that of the numerous fusion welding techniques $[18,19]$. But, inspite of the simple \& user friendly principle of joining, there seems to exist various unexplored areas and research complications arising due to the anomalies occurring internal flow of plasticized materials due to the exhilarating action of the FSW tool pin geometry and by the generated heat arising from friction between shoulder and workpiece surface [20-23]

Detailed illustration of the thermo mechanical anomaly occurring between the flat metal plates to be joined and the employed FSW tool pin will enable optimization of welding parameters, perfect design of FSW tool, extending the application of the FSW to various new dimensions [24 - 26]. For better \& perfect understanding of the FSW process, especially w.r.t to the tool temperatures \& 
flow of heat, there exist the need of employing both mathematically developed simulation models and real experimentation methods [27 - 31].

It was revealed by various experimental researchers [32 - 36] that, the joining parameters of FSW, the flow of plasticized material, interface anomaly of FSW tool and workpiece surface etc have been proven to significantly influence the volume of heat generation during of joining of $\mathrm{Al}$ alloys using FSW. As majority of these experimental research works have concentrated their research towards the measurement of the temperature over distinct \& limited regions of the workpiece surface, there exists a vital \& unavoidable need for analysing \& understanding the temperatures, flow of generated around the FSW tool pin profile, to derive a mathematical model to predict the flow of temperature for various FSW tool pin profiles, the role of the geometrical design of the various pin profiles in regulating the flow of generated frictional heat and to compare these model results with that of the actual experimental data.

In this numerical \& experimental research work, a thermo mechanical model for was formulated and developed using the COSMOL software to predict the temperature diffusion around the FSW tool with 4 unique profile geometries (namely cylindrical, taper cylindrical, square and triangle) and to understand the role, impact of these pin geometries in regulating the generated frictional heat. The predicated results (i.e., simulated peak temperature) of the formulated mathematical model are then compared \& validated with that of the actual experimental results and analysed.

\section{EXPERIMENTAL DETAILS}

\subsection{Material, Machine and Tool Pin Geometries}

In this experimental research, wrought AZ80A $\mathrm{Mg}$ alloy was investigated and a uniquely developed \& fabricated FSW machine (semi-automatic category) was employed to fabricate joints for the flat AZ80A Mg work pieces with the dimension of $50 \mathrm{~mm}$ width and $100 \mathrm{~mm}$ length 
together with a thickness of 5mm. The employed FSW machine comprised of a spindle motor with $5 \mathrm{~kW}$ capacity, working table measuring $810 \mathrm{~mm}$ in length and $400 \mathrm{~mm}$ in width.

Several experimental investigations [37 - 39] have proven that High-Speed Steel graded M35 metal is an ideal material for fabricating FSW tools, due to their excellent resistance to wear, superior toughness and this material possesses a larger resistance to softening, especially at peak temperatures around $500-550^{\circ} \mathrm{C}$, making it more desirable for employment for higher operational speeds. Based on these reasons, in this experimental research, High-Speed Steel graded M35 material was used to fabricate the various required FSW tools. FSW tools having four distinctly unique pin geometries, including cylindrical, taper cylindrical, square and triangle as seen in the Figure 1 were designed and fabricated.
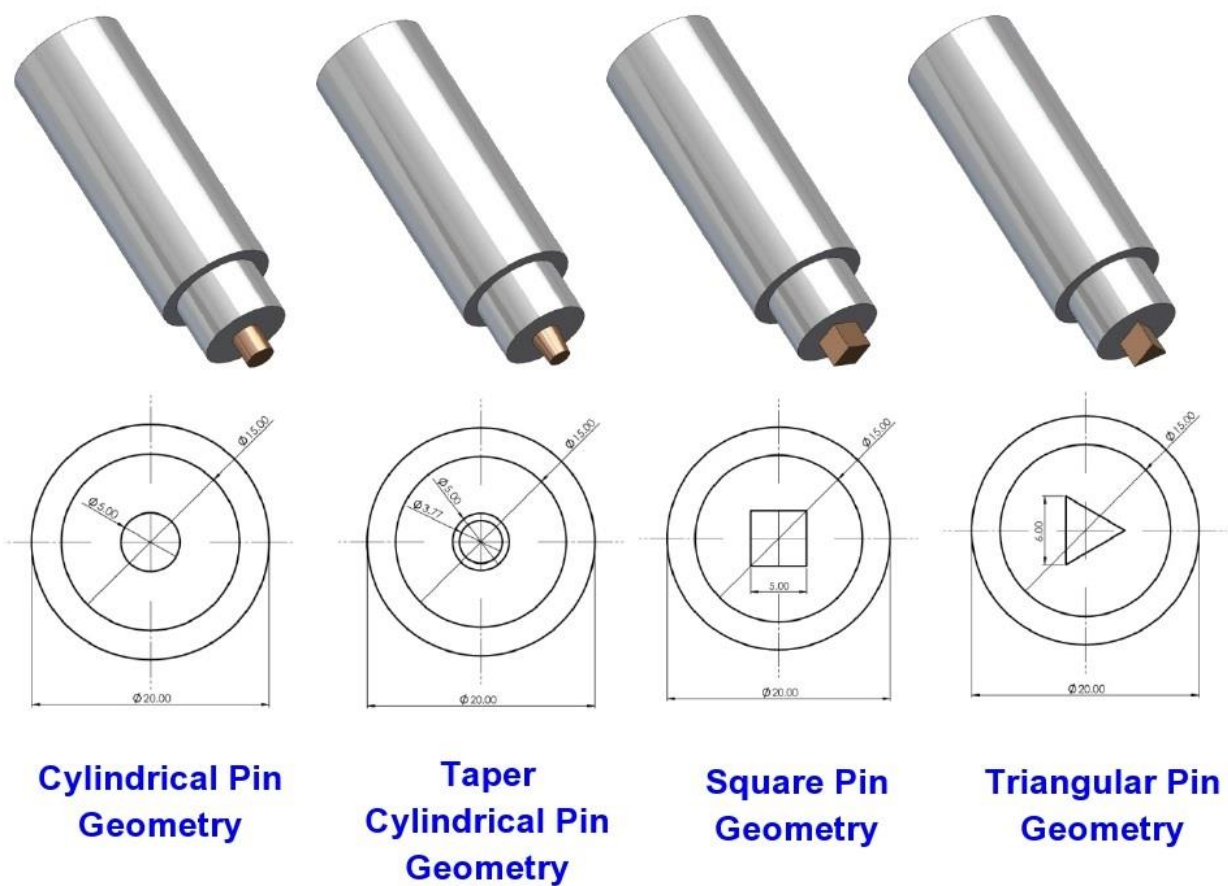

Fig.1. Diagrammatic representation of the FSW tools with four different pin geometries employed in this investigation.

Except the geometry of the tool pin, all other dimensions namely tool outer \& inner shoulder diameter, pin length, shoulder lengths etc remains the same for all the four FSW tools. All the four 
FSW tools have a $20 \mathrm{~mm}$ outer shoulder diameter (for $50 \mathrm{~mm}$ length), $15 \mathrm{~mm}$ diameter for inner shoulder (for $10 \mathrm{~mm}$ length) and a pin length of $4.85 \mathrm{~mm}$.

\subsection{Tool \& Workpiece Temperature Measurement Setup}

In this numerical \& experimental research, the temperature on the surface of investigational workpiece (AZ80A Mg) were measured by the employment of thermocouples fabricated out of $\mathrm{Cr}$ Al wires.

Figure 2 graphically illustrates the arrangement \& location of the employed thermocouples on various regions of the AZ80A Mg alloy flat plates both on AS and RS.

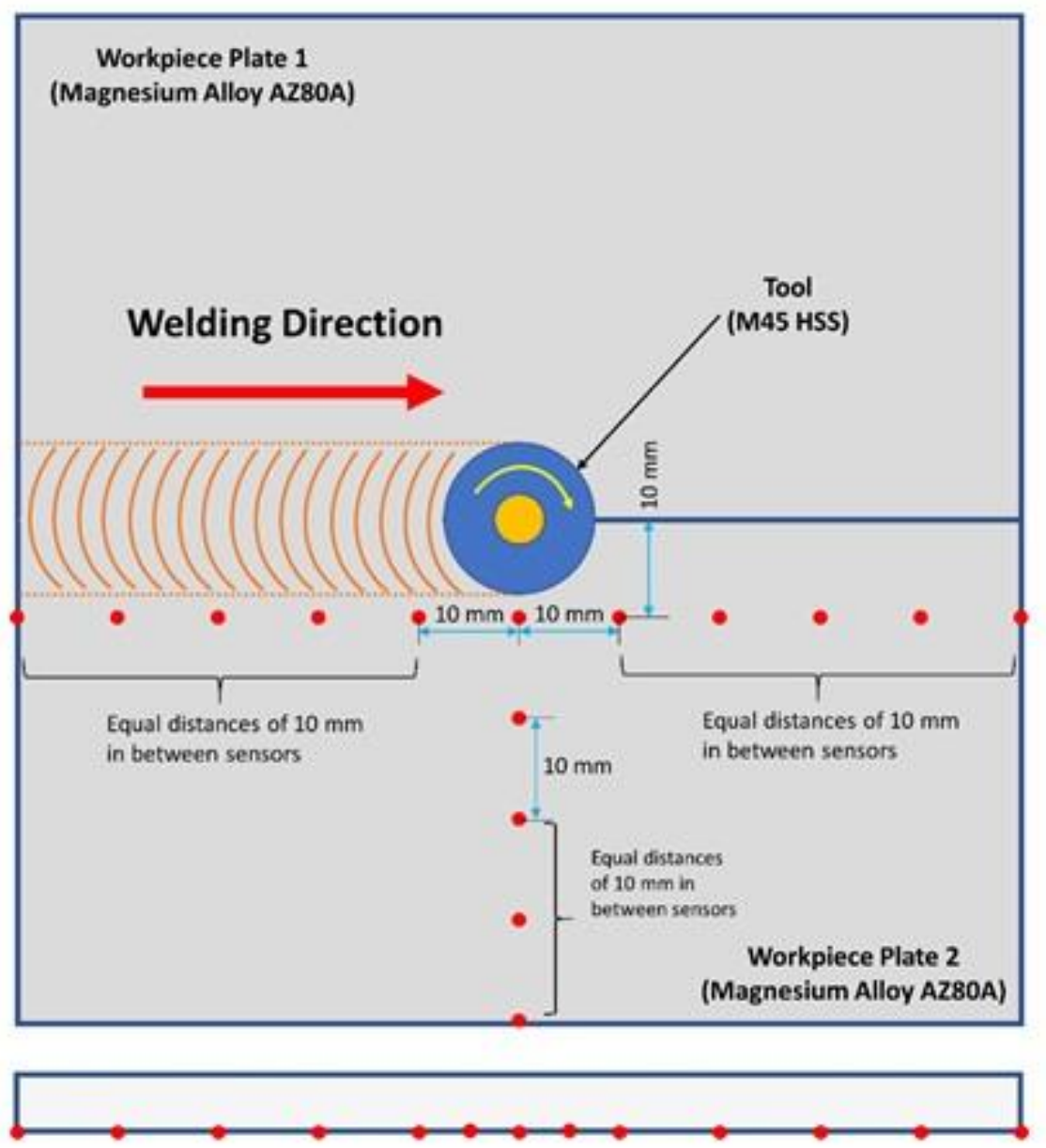

\section{Centre line}

bottom side sensors

Fig.2. Schematic arrangement \& location of the employed thermocouples on various regions of the AZ80A Mg alloy flat plates 
3 different categories under which measurement of temperature was carried out includes (a) Line of axis along the bottom side (b) axis of transverse on the top side and (c) at an offset of $10 \mathrm{~mm}$ on the top side from the axial line. Measurement of temperature on the FSW tool side was employed for determining the temperature of the FSW process, as the temperature of the FSW tool will be in stable position and state, when compared with that of the other regions during the joining of the AZ80A Mg plates. The arrangements of the thermocouples in the interior regions of the employed FSW tools are graphically represented in the Figure 3. The various interior locations of the placement of the thermocouples inside the FSW tool include the tip of the tool pin geometry, inner shoulder region and root of the FSW tool pin geometry.

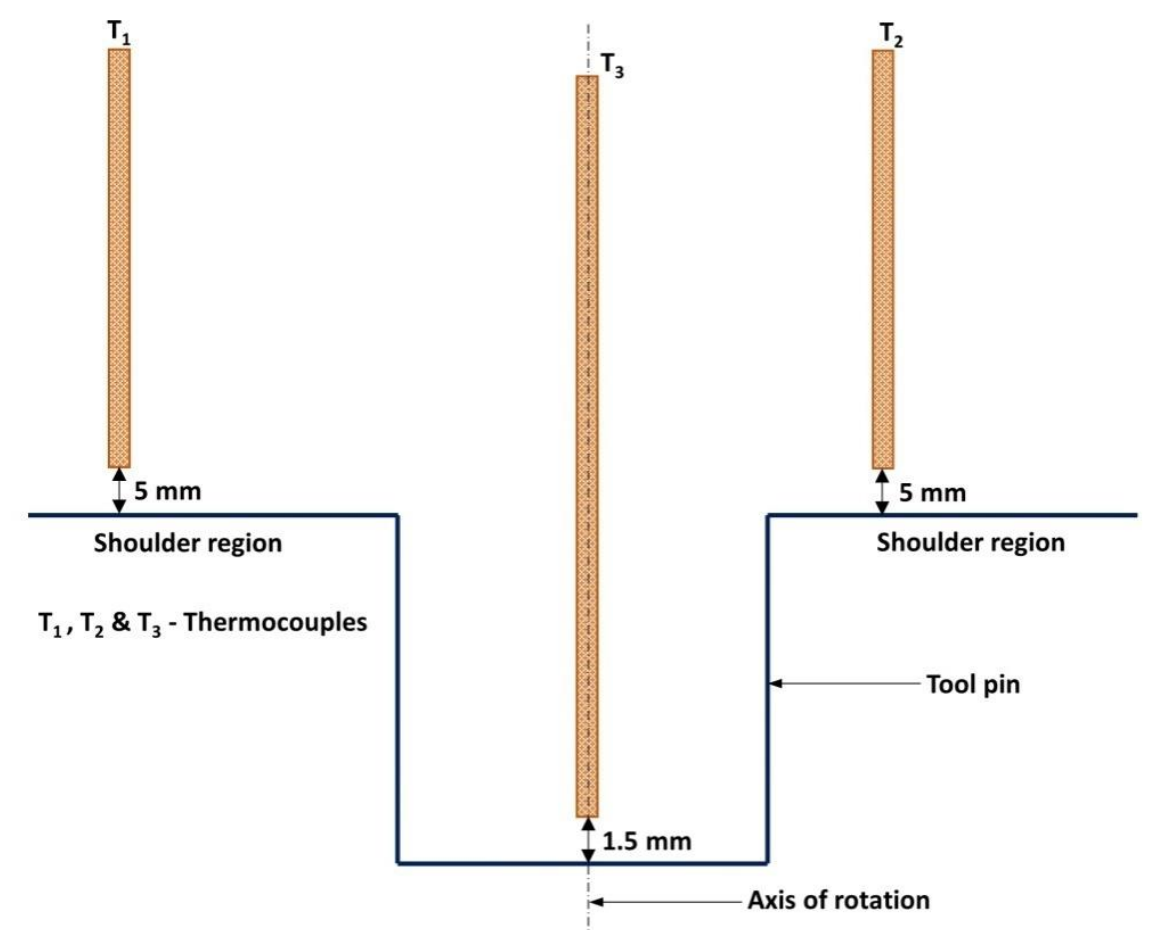

Fig.3. Cross Sectional graphical illustration of the arrangements of the thermocouples in the interior regions of the employed FSW tools

All the thermocouples were placed in their respective above mentioned positions arrangements of the thermocouples in the interior regions of the employed FSW tools at a distance of around $1 \mathrm{~mm}$ from the surfaces of the FSW tool to calibrate the temperature as nearer to the temperature at the 
workpiece / tool interface, as far as possible. The various conditions of the proposed experimental research are mentioned in Table 1.

Table 1: Conditions of experimental investigations adopted during the joining of AZ80A Mg alloy by FSW

\begin{tabular}{|c|c|c|}
\hline S.No. & Parameter description & Specification \\
\hline 1. & Workpeice & AZ80A Mg alloy \\
\hline 2. & FSW tool & HSS: M35 grade \\
\hline 3. & FSW tool pin geometry & Cylindrical, Square, Triangle \& Taper Cylindrical \\
\hline 4. & Rotational speed of FSW tool & $1.48 \mathrm{~mm} / \mathrm{min}$ \\
\hline 5. & Speed of traverse of FSW tool & $3.64 \mathrm{kN}$ \\
\hline 6. & Force on the FSW tool (axially) & \\
\hline
\end{tabular}

\subsection{Formulation of Thermo mechanical model}

Several modelling based experimental investigations [40 - 42] reveals us that, the issues related with differential equations can be dealt by approaching the enario by means of a mathematical strategy. In this experimental research, the formulated process model for fabricating $\mathrm{AZ} 80 \mathrm{~A} \mathrm{Mg}$ alloy joints through employment of FSW tools (with four unique Pin geometries namely cylindrical, square, triangle, taper cylindrical) was devised with the help of COMSOL Multiphysics transfer of heat component.

A thermo mechanical based process modelling is the distribution and bisection of a geometric sector into restricted number of fundamental points and primitive volumes. In this formulated thermo mechanical process model, a definite assessment of the overseeing limit prerequisite regulating each nodal point and its neighbouring focuses are also characterized. Observational conclusions are also acquired for the above mentioned equational structures, emerging from those definite assessments. As it is evident that, the numerical dominion is well-proportioned along the line of weld, it is sufficient to consider only half of the flat plate of investigational workpiece, in 
the course of formulation of the process model $[43,44]$. The generated computational domain for the joining of AZ80A mg alloy by FSW technique is shown in the Figure 4 and it can be visualized that, the surface of the workpiece is attached with two absolute dominion along the direction of $\mathrm{x}-$ axis.

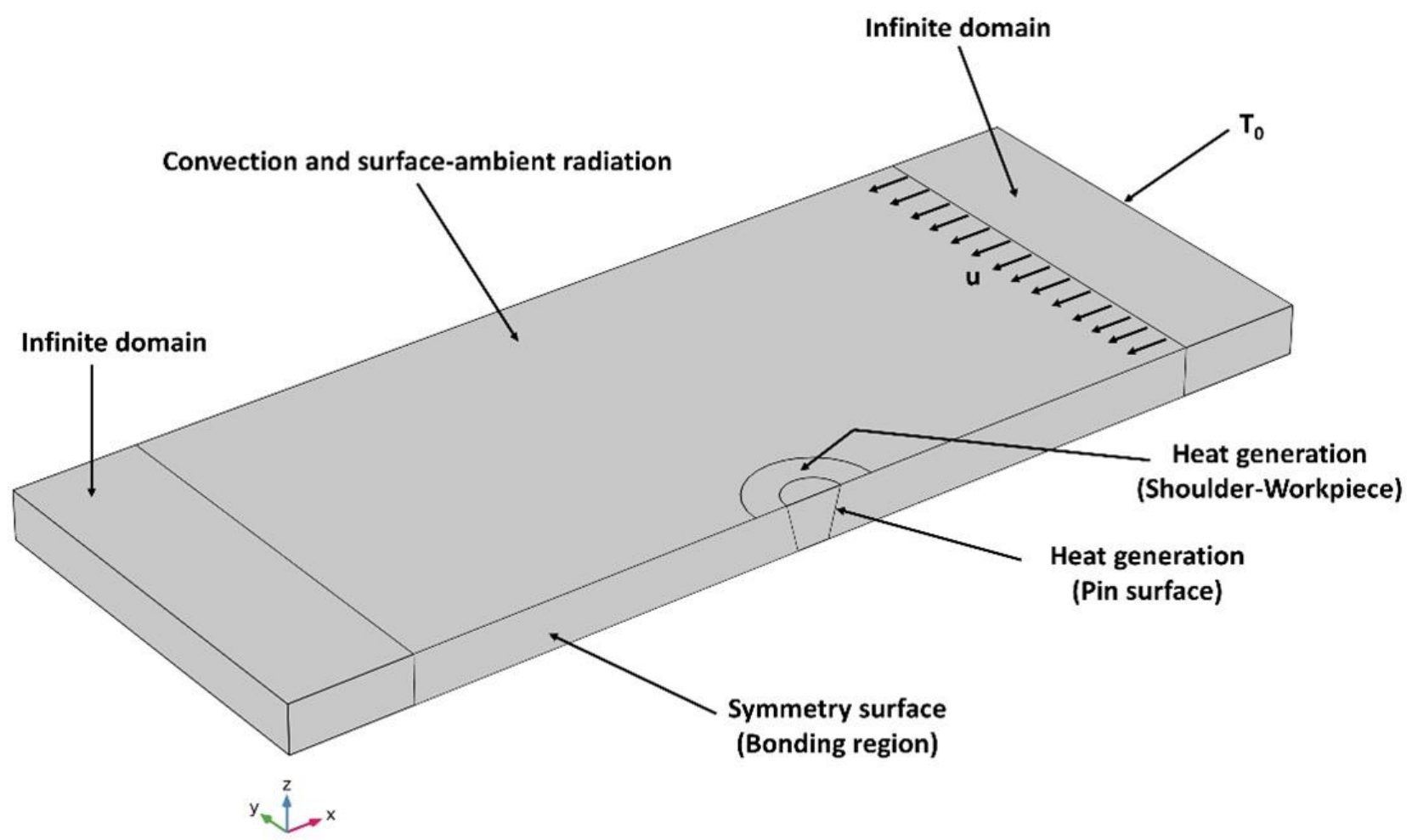

Fig.4. Diagrammatic view of the formulated geometry of process model for joining of AZ80A Mg by FSW technique

Apart from this, the below mentioned elemental presumptions were considered in formulating the thermo mechanical process model:-

- Angle of inclination of the FSW tool is neglected

- The various cycles of weld including $1^{\text {st }} \& 2^{\text {nd }}$ dwell, cycles of retraction etc are excluded

- The numerical assessment based on the general presumption of the consistent contact shear stress $\tau_{\text {con }}$ has been taken into account 
It was also assumed that, flow of heat into the workpiece will not take place, when the regional temperature attains the melting temperature of the workpiece.

\section{THERMO MECHANICAL PROCESS MODELLING}

\subsection{Heat transfer in the AZ80A Mg alloy surface}

Volume of transmission of heat happening above the surface of investigational workpiece during FSW in a movable system of coordinate is governed by the equation:

$$
\rho C_{p} u . \nabla T+\nabla \cdot(-k \nabla T)=Q
$$

In the above equation, $\mathrm{T}$ represents the generated temperature, $\mathrm{Cp}$ is the quantity of heat, $\rho$ represents the density, the conductivity of heat being denoted by $\mathrm{k}$ and $\mathrm{u}$ represents the traversing speed of the FSW tool.

\subsection{Generation of heat from tool shoulder}

Similarly, the various equations governing the generation of heat in between the region of interface of the FSW tool shoulder and AZ80A Mg (workpiece) for the employed FSW tools with 4 different pin geometries are as follows [45, 46]:

$Q_{\text {shou }, c y}=\frac{2}{3} \pi \omega \tau_{\text {con }}\left(R_{\text {shou }}^{3}-R_{\text {pin }}^{3}\right)$

$Q_{\text {shou,tcy }}=\frac{2}{3} \pi \omega \tau_{\text {con }}\left(R_{\text {shou }}^{3}-R_{\text {pin, } \max }^{3}\right)$

$Q_{\text {shou }, \text { sq }}=\frac{2}{3} \pi \omega \tau_{\text {con }} R_{\text {shou }}^{3}-\frac{1}{3 \sqrt{2}} \pi \omega \tau_{\text {con }}^{*} . S_{\text {sq }}^{3}$

$Q_{\text {shou,tri }}=\frac{2}{3} \pi \omega \tau_{\text {con }} R_{\text {shou }}^{3}-\frac{2}{9 \sqrt{3}} \pi \omega \tau_{\text {con }}^{*} . S_{\text {tri }}{ }^{3}$

In the above equations, $Q_{\text {shou }}$ represents the heat generated around each of the employed FSW tools, the angular speed of rotation of the FSW tools are denoted by $\omega$, the shear stress of contact 
by means of $\tau_{\text {con }}, R_{\text {shou }}$ denotes the employed tool shoulder's radius, the radius of the pin of employed FSW tools are indicated by $\mathrm{R}_{\text {pin }}$ and $\mathrm{S}$ indicates the side length of the square and triangle pin profiles of the FSW tools

\subsection{Generation of heat from pin of FSW tool}

The equations governing the generation of heat by the pins of the various employed FSW tools are as follows $[45,46]$ :

$$
\begin{aligned}
& Q_{p i n, c y}=2 \pi \omega R_{p i n}^{2} \tau_{c o n}^{*} H_{p i n} \\
& Q_{p i n, t c y}=\frac{\pi}{2} \omega \tau_{c o n}^{*} \frac{H_{p i n}}{\cos \alpha}\left(R_{p i n, \max }+R_{p i n, \min }\right)^{2} \\
& Q_{p i n, s q}=\omega \tau_{c o n}^{*} H_{p i n} S_{s q}^{2} \\
& Q_{p i n, t r i}=\frac{\omega}{2} \tau_{c o n}^{*} H_{p i n}\left(\frac{S_{t r i}}{\sqrt{3}}\right)^{2}
\end{aligned}
$$

In the above equations, the quantity of heat generated by the pin of employed tools is denoted by Qpin, the height of the pin of employed tools by $\mathrm{H}_{\text {pin, }}$ and in the case of a taper cylindrical pin, $\mathrm{R}_{\text {pin,min }}$ denotes the bottom radius of the taper pin and $\mathrm{R}_{\mathrm{pin}, \mathrm{max}}$ denotes the top radius of the taper pin.

\subsection{Heat loss}

The convection taking place in a natural manner and radiation prevailing due to surface to element scenarios are the two most important criterions, due to which the AZ80A Mg alloy workpieces lose the heat on their lower and upper regions. The relevant equations of flow of heat corresponding to the above mentioned regions of the workpiece are as follows:

$$
\begin{aligned}
& q_{u p}=h_{u p}\left(T_{0}-T\right)+\varepsilon \cdot \sigma \cdot\left(T_{a m b}^{4}-T^{4}\right) \\
& q_{\text {down }}=h_{\text {down }}\left(T_{0}-T\right)+\varepsilon \cdot \sigma \cdot\left(T_{a m b}^{4}-T^{4}\right)
\end{aligned}
$$


In the above equations, flow of heat on the upper region of workpiece is indicated by $\mathrm{Q}_{\text {up }}$ in $\mathrm{W} / \mathrm{m}^{2}$, flow of heat on the lower region of workpiece is indicated by $\mathrm{Q}_{\text {down }}$ in $\mathrm{W} / \mathrm{m}^{2}$, To represents the reference of temperature (Kelvin), temperature onthe surface of the workpiece by T (Kelvin), $\varepsilon$ denotes the emissivity of the workpiece of the surface, $\sigma$ denotes the constant of Stefan-Boltzmann, the air temperature ambient by $\mathrm{T}_{\mathrm{amb}}$ (Kelvin) and the coefficients of transmission of heat are

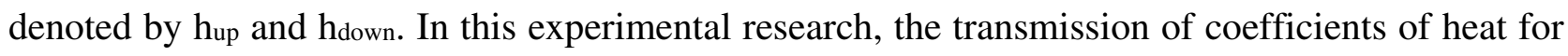
bottom side was considered to be $12.25 \mathrm{~W} / \mathrm{m}^{2} \mathrm{~K}$ and $6.25 \mathrm{~W} / \mathrm{m}^{2} \mathrm{~K}$ for topside of the workpiece respectively.

\subsection{Temperature reliant characteristics of workpiece \& Tool Materials}

Table 2 describes the various temperature reliant characteristics of workpiece (AZ80A $\mathrm{Mg}$ ) and Table 3 describes the properties of the employed tool, i.e., M35 grade high speed steel (FSW tool) which are considered during the framing of the established thermo mechanical process model

Table 2: Temperature reliant characteristics of workpiece

\begin{tabular}{|c|l|l|l|l|l|l|l|l|}
\hline \multicolumn{7}{|c|}{ Temperature reliant characteristics - AZ80A Mg alloy } \\
\hline $\begin{array}{c}\text { Specific Heat } \\
(\mathrm{J} / \mathrm{Kg} . \mathrm{K})\end{array}$ & 0.975 & 1.032 & 1.076 & 1.105 & 1.125 & 1.141 & 1.155 & 1.165 \\
\hline $\begin{array}{c}\text { Thermal } \\
\text { Conductivity } \\
(\mathrm{W} / \mathrm{m} . \mathrm{K})\end{array}$ & 59.2 & 63.3 & 68.2 & 73.4 & 77.3 & 82.1 & 92.9 & 98.9 \\
\hline $\begin{array}{c}\text { Density }\left(\mathrm{Kg} / \mathrm{m}^{3}\right) \\
\text { Temperature }\left({ }^{\circ} \mathrm{C}\right)\end{array}$ & 1806 & 1801 & 1793 & 1786 & 1778 & 1770 & 1763 & 1755 \\
\hline
\end{tabular}

Table 3: Properties of M35 grade high speed steel

\begin{tabular}{|l|c|}
\hline \multicolumn{1}{|c|}{ Properties } & Value \\
\hline Specific Heat ( J/Kg.K) & 465 \\
\hline Poisson's ratio & 0.28 \\
\hline Young's modulus (Gpa) & 207 \\
\hline
\end{tabular}




\begin{tabular}{|l|c|}
\hline Density $\left(\mathrm{kg} / \mathrm{m}^{3}\right)$ & 8140 \\
\hline Thermal Conductivity (W/m.K) & 26 \\
\hline
\end{tabular}

\subsection{Irregular mesh}

From various experimental observations [47 - 49], it is proven that, there exists a need for placing greater number of nodes of grid along the circumference of the FSW tool pin, for obtaining results with high degree of accuracy. This arises because of the reality that, the extent and proportion of the FSW tool pin is very smaller, comparing it with that of the surface of workpiece. Figure 5 graphically portrays the position of the countless, infinite nodes of grid placed around the entire circumferential region of the pin geometries (namely cylindrical, square, triangle \& taper cylindrical) of the employed FSW tools.

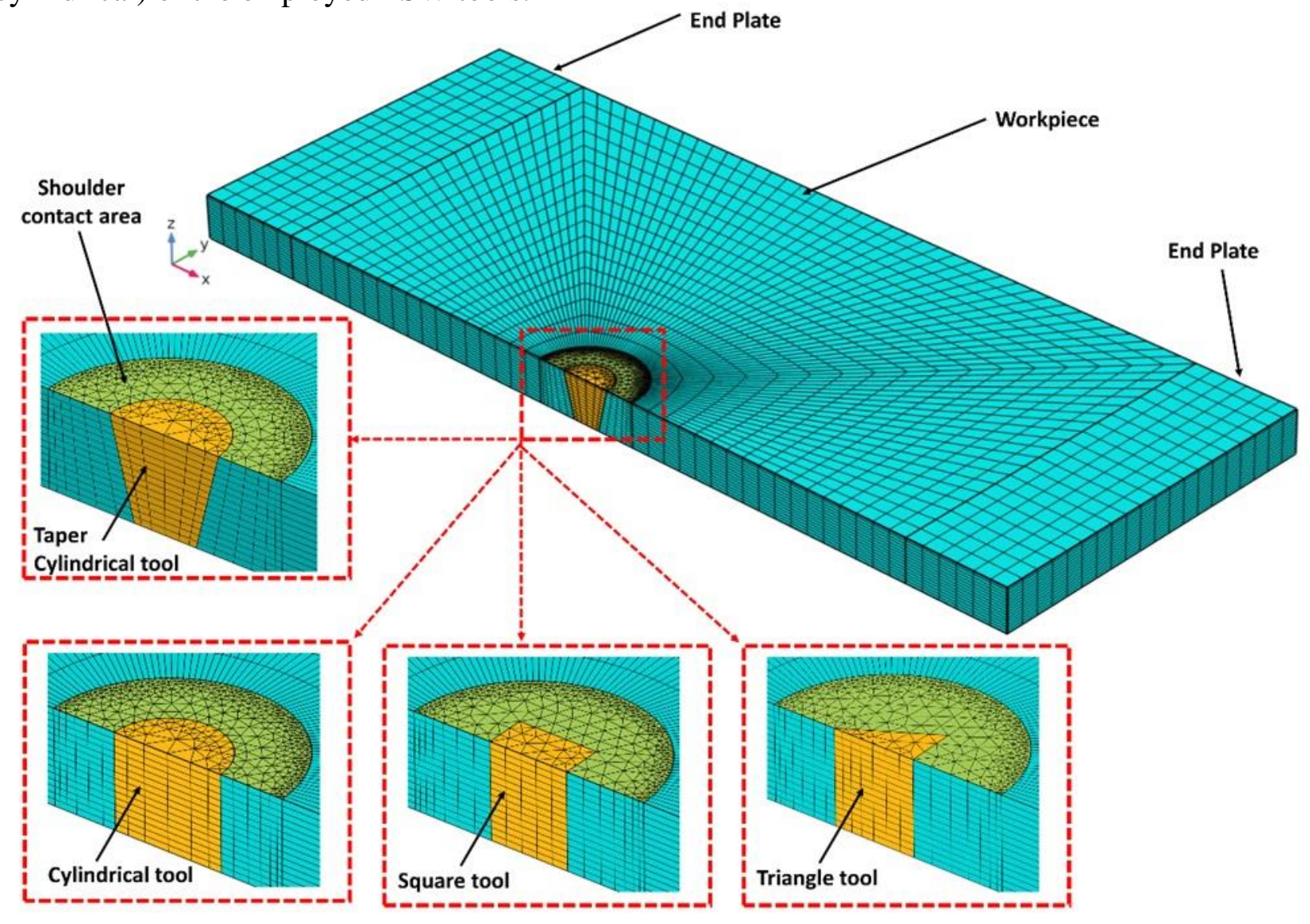

Fig.5. Graphical representation of the position of the countless, infinite nodes of grid placed around the entire circumferential region of the different pin geometries 
Table 4 provides the complete description of the important criterions taken into account for the generation of the mesh in the established thermo mechanical modelling process.

Table 4: Description of the important criterions for mesh generation

\begin{tabular}{|c|c|c|c|c|}
\hline \multirow{2}{*}{ Description of parameters } & \multicolumn{4}{|c|}{ Specification } \\
\cline { 2 - 5 } & Cylindrical & Taper Cylindrical & Square & Triangle \\
\hline Elemental Size (maximum), mm & 2.5 & 2.5 & 2.5 & 2.5 \\
\hline Elemental Size (minimum), mm & 0.026 & 0.026 & 0.026 & 0.026 \\
\hline Elemental growth rate (maximum) & 1.3 & 1.3 & 1.3 & 1.3 \\
\hline prism elements & 11160 & 11160 & 9585 & 10065 \\
\hline hexahedral elements & 24000 & 24000 & 24000 & 24000 \\
\hline triangular elements & 1488 & 1488 & 1278 & 1342 \\
\hline quadrilateral elements & 7580 & 7580 & 7520 & 7535 \\
\hline edge elements & 794 & 794 & 801 & 788 \\
\hline
\end{tabular}

\subsection{Analytical modelling scheme}

The analytical and numerical models pertinent to transmission of heat resulting from conduction, radiation and convection are established by employing the steady-state heat transmission, established on solids interface theory [50]. The thermo mechanical process model has been formulated in such a way that, when the temperature (peak) reaches the melting temperature of the workpiece, the heat input generating from the tool pin will get adjusted to zero automatically. In this experimental research, the temperature of melting of the workpiece (AZ80A Mg) is less, when comparing it with that of the experimentally generated heat by friction. So, on occasions, when the simulated peak temperature approaches value equal to the melting temperature of $\mathrm{AZ} 80 \mathrm{~A} \mathrm{Mg}$, the 
generated heat by friction will get adjusted to value of zero immediately. In better mathematical words, it can be understood as,

$q=0 ;\left(T \geq T_{m e l t}\right)$

\section{VALIDATION OF ESTABLISHED MODEL}

\subsection{Experimental Validation of $T_{\max }$}

Figure 6 graphically illustrates the differences in peak temperatures between the actual experimental values and the mathematical model simulation values for the four different types of the pin geometries (namely cylindrical, taper cylindrical, square and triangle) of the FSW tools.

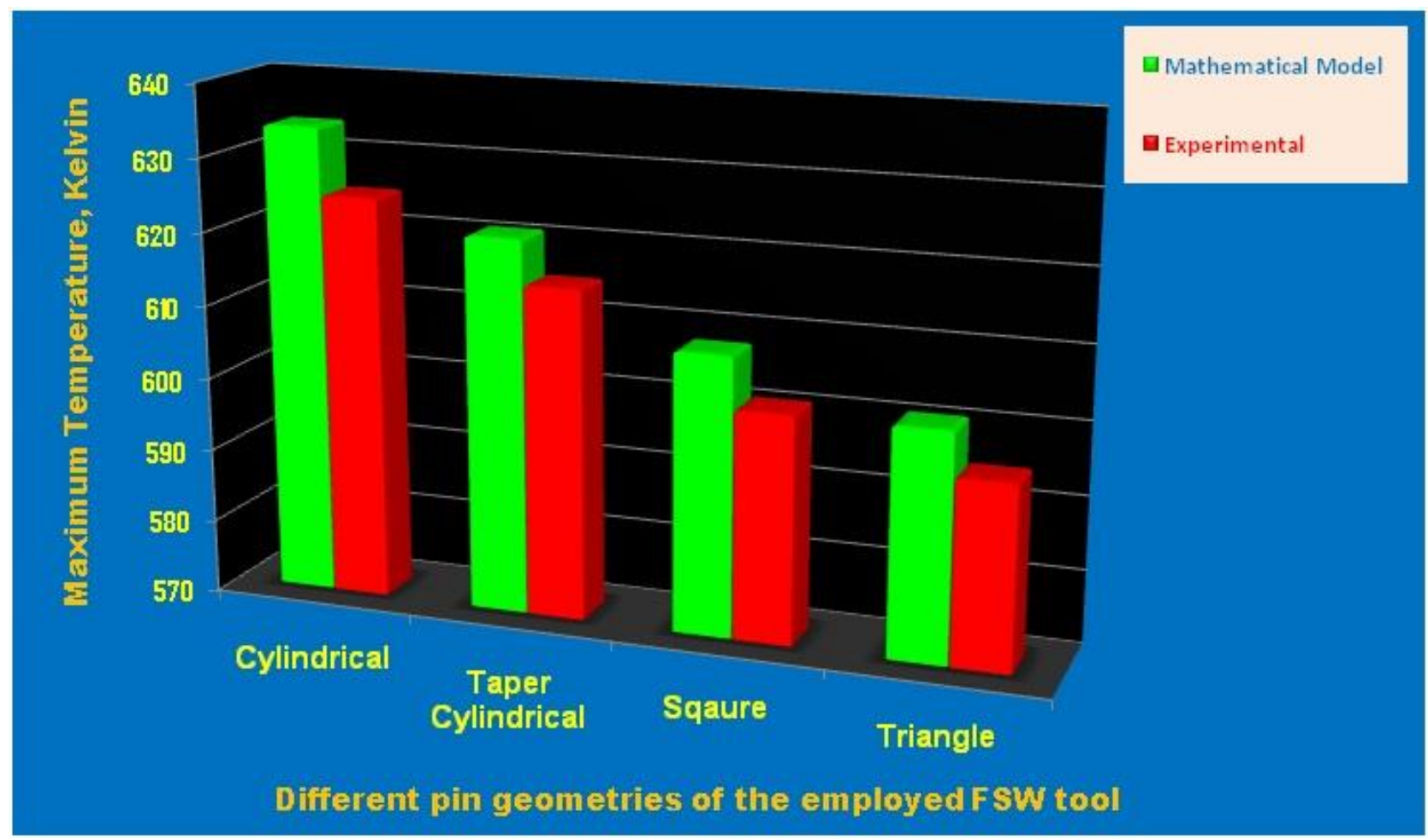

Fig.6. Graphical comparison of the differences in peak temperatures between the actual experimental values and the mathematical model simulation values

The peak temperature values of the formulated thermo mechanical process model are found to be consistent with that of the actual experimental results and exhibited relatively very small variation \& completely unbiased. The percentage difference between the experimental and mathematical model simulation values obtained for the maximum temperature are $1.42 \%, 0.96 \%, 1.18 \%$ and 
$0.98 \%$ respectively for FSW tools with cylindrical, taper cylindrical, square and triangle pin geometries.

\subsection{Comparison of anticipated and experimental $\boldsymbol{T}_{\max }$}

In this experimental research, anticipated peak temperature $\mathrm{T}_{\max }$ was validated against experimentally measured temperature values and found to coincide with one another.
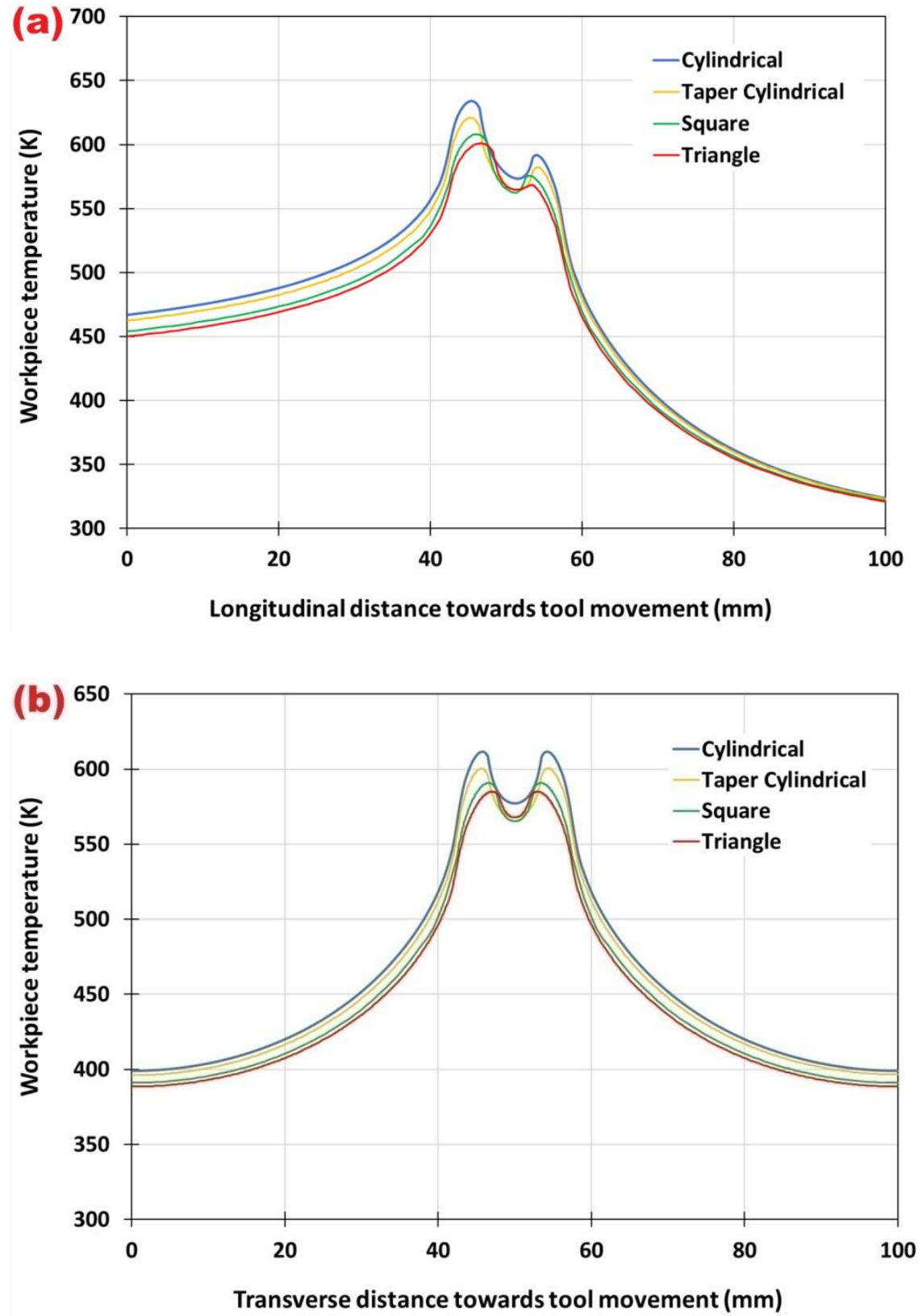

Fig.7. Graphical comparison of the Variations in temperature (a) along the longitudinal axis and its offset and (b) along the transverse axis behind tool movement and its offset. 
Results of experimental runs carried out at the optimised process parameter conditions (i.e, tool rotational speed $=818 \mathrm{rpm}$; force applied on the FSW tool axially $=3.64 \mathrm{kN}$; rate of traversing of tool over workpiece $=1.48 \mathrm{~mm} / \mathrm{s}$ ) were taken as the inputs for generating line plots and contours $[3,44]$. The variations of temperature on the surface of the workpiece w.r.t the offset lines and bonding lines, when the tool approaches the workpiece centre part, for the various employed FSW tools with the different pin geometries are illustrated in the Figure 7 (a) \& (b).

\subsection{Analysis of temperature distribution}

Figure 8 decribes in detail, the generated temperature contour graphs on the top surfce of the work piece and on the bonding surfaces for tools with different pin geometries.

Figure 9 illustrates the generated temperature distribution on the tool contact area w.r.t work piece surface and on the different tool pin geometries of the FSW tools. From these various temperature distribution graphs, it can be understood that, the peak value of the generated temperature occurs around the portions of the work piece, which are dominated by exhilarating action of rotating shoulder of tool.

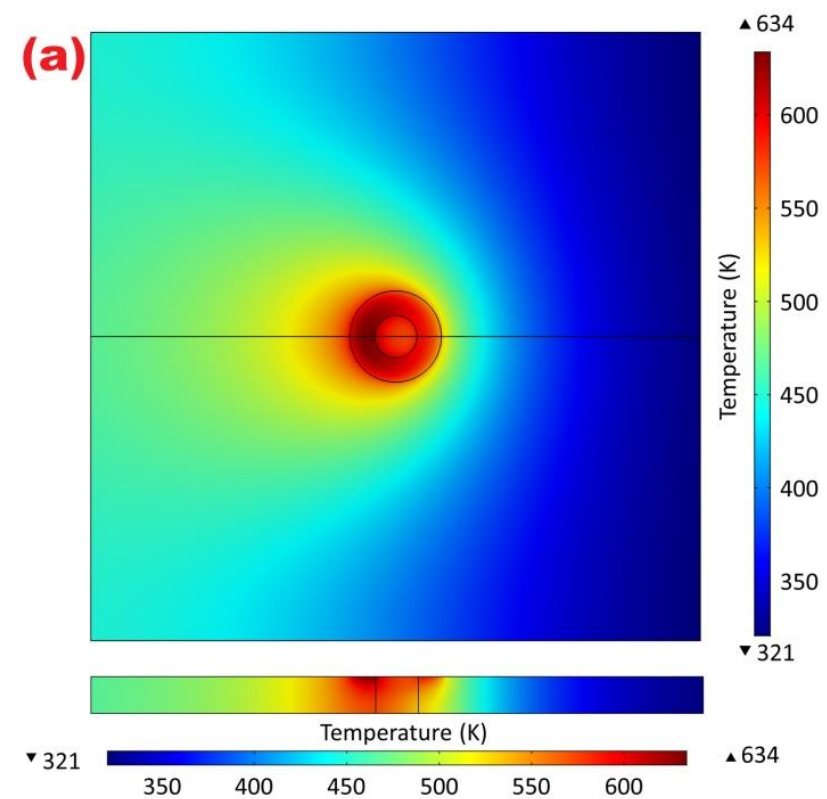

Cylindrical pin

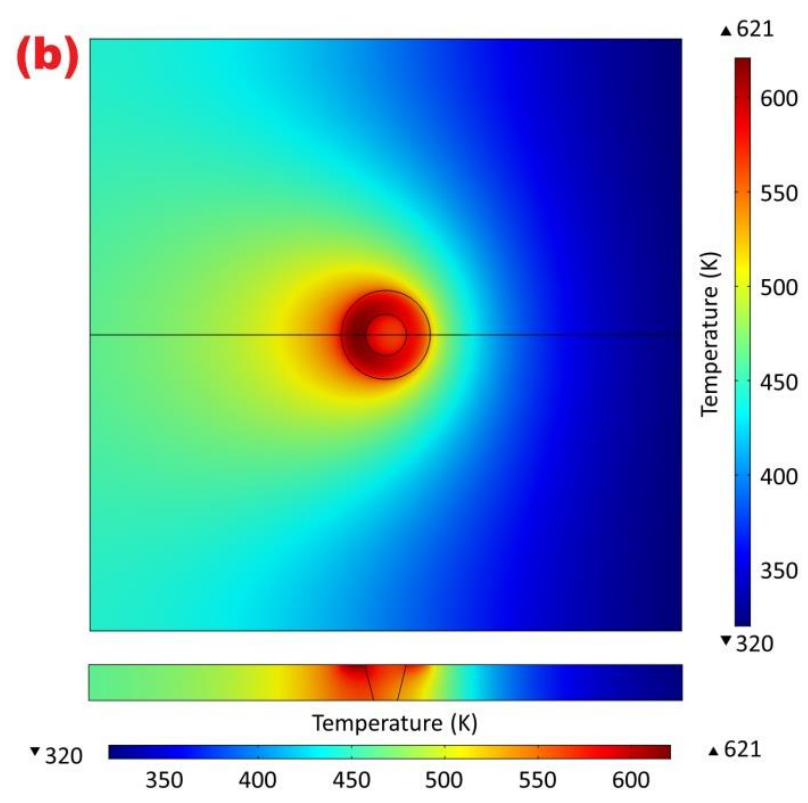

Taper cylindrical pin 

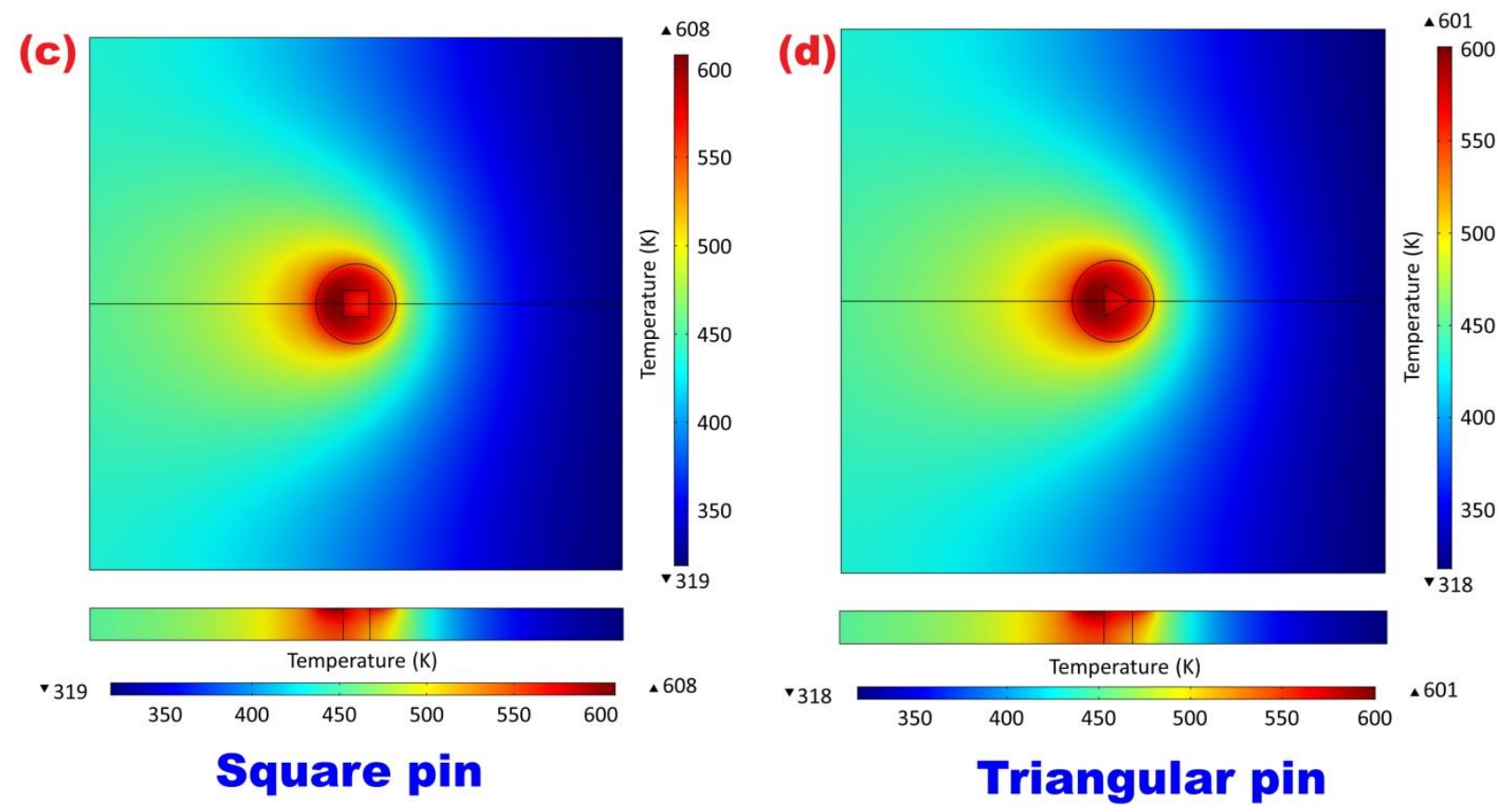

Fig.8. Graphical illustration of the generated temperature contour graphs on the top surface of the work piece and on the bonding surfaces for tools with different pin geometries namely (a) Cylindrical Pin (b) Taper Cylindrical Pin (c) Square Pin and (d) Triangular Pin

It can be realized that, tool with cylindrical pin geometry has generated maximum value of peak temperature (i.e., $634 \mathrm{~K}$ ) and the FSW tool with the triangular pin geometry has generated minimum value of peak temperature (i.e., $601 \mathrm{~K}$ ). The FSW tool with the square pin geometry has generated a peak temperature of $608 \mathrm{~K}$.

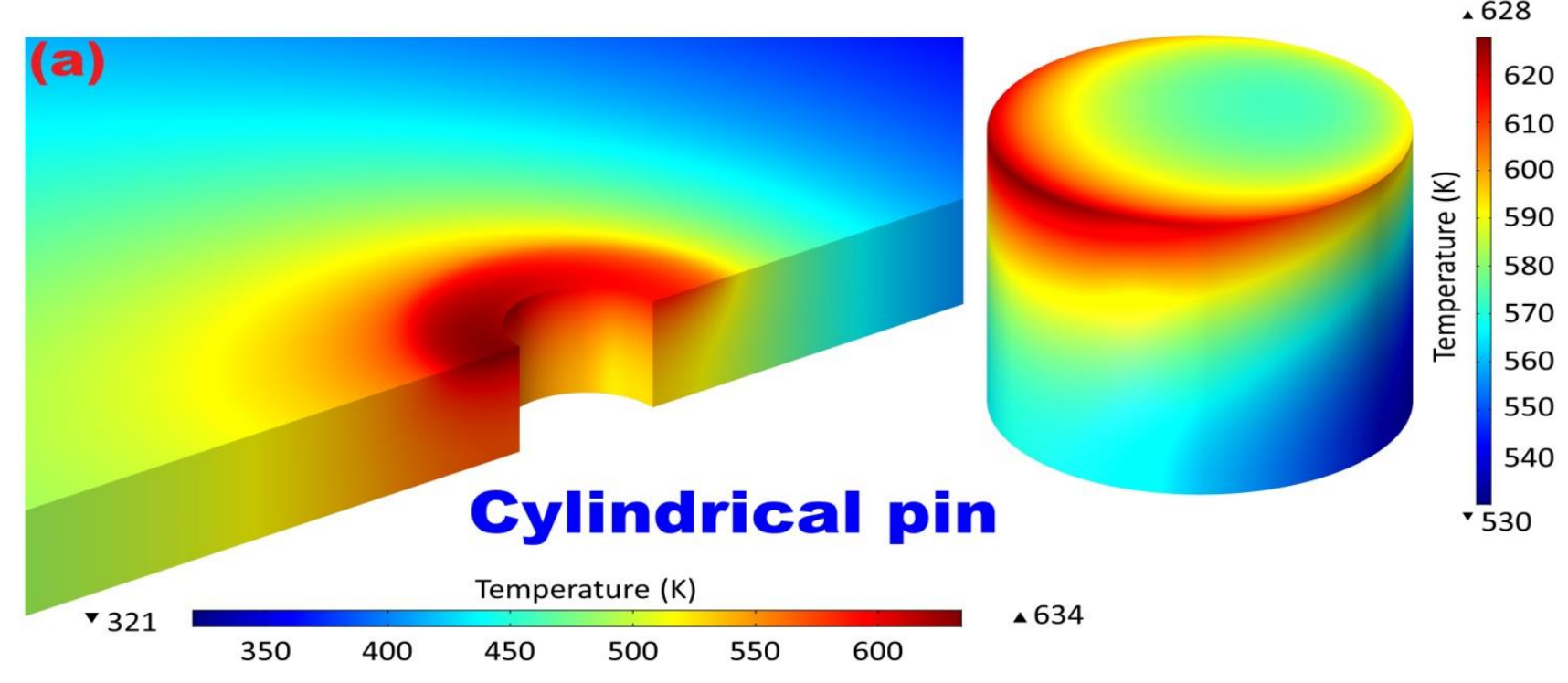




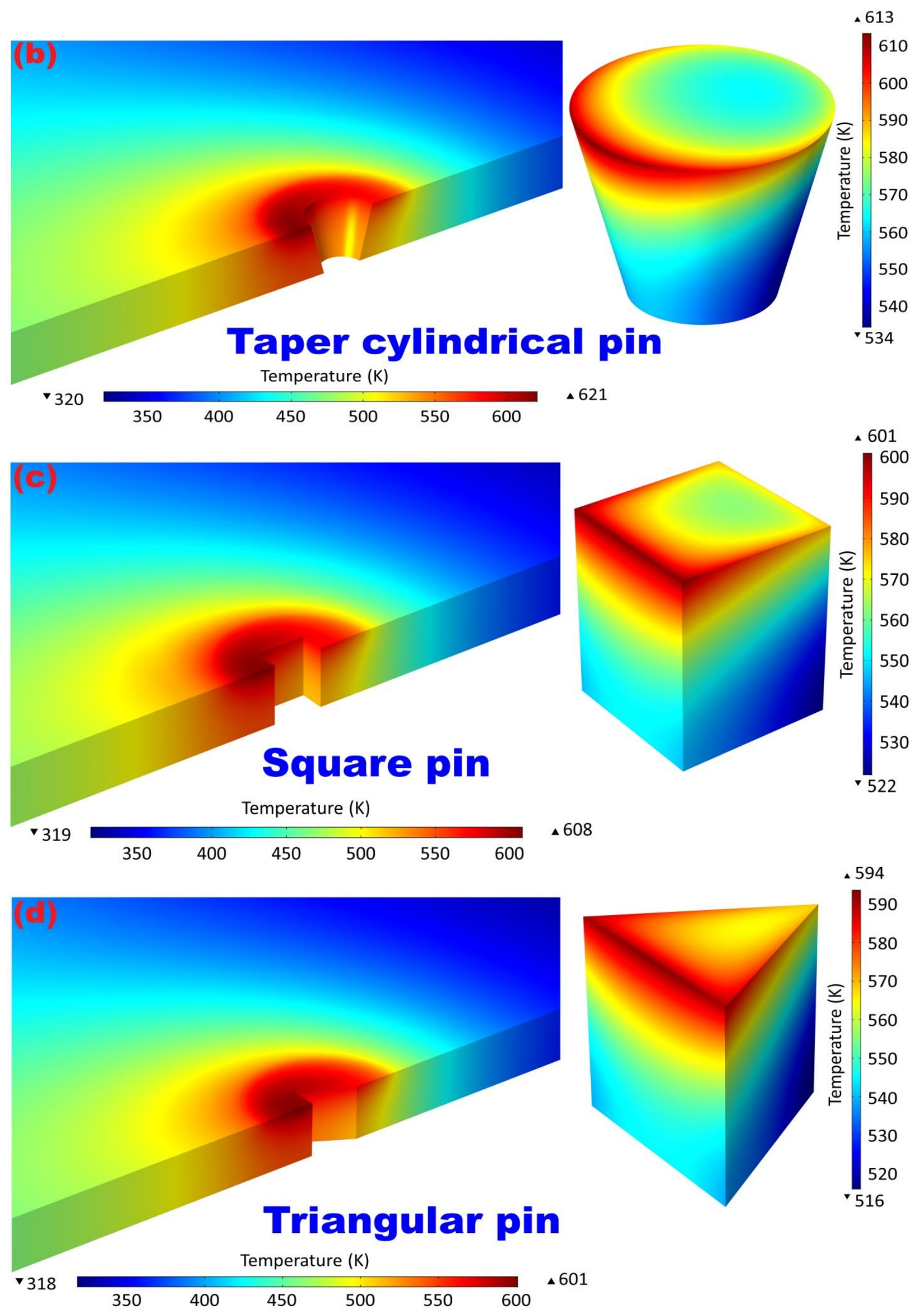


Fig.9. Graphical illustration of the generated temperature distribution on the tool contact area w.r.t work piece surface and on the different tool pin geometries of the FSW tools including (a) Cylindrical Pin (b) Taper Cylindrical Pin (c) Square Pin and (d) Triangular Pin

The ideal peak temperature value of $621 \mathrm{~K}$ was found to be generated by tool with taper cylindrical pin geometry, which is nearly $81-82 \%\left(348^{\circ} \mathrm{C}\right)$ of the melting temperature $\left(427^{0} \mathrm{C}\right)$ of the work piece (i.e., AZ80A Mg alloy).

\section{INFERENCES, OBSERVATIONS \& DISCUSSIONS}

\subsection{Examination of the micro structural images}

Figure 10 describes the optical microstructrual images of joints fabricated employing tools with four different pin geometries under optimized process parameter conditions. From these microstructural images, it can be observed that, there exists some variations in size of the grains in the fabricated joints and this variations in grain size is due to the employment of the four different pin geometries, as the tool material and other operating conditions were kept completely constant for the entire set of experimental runs.

By inspecting these microstructures, it can be presumed that, the welded specimen obtained by employing tool with taper cylindrical pin geometry (with other process parameters being constant) is found to possess very exceptional sized grains, distributed consistently \& homogenously, in comparison with remaining three welded joint's microstructures. This unique transformation of grain structures is a direct evident to the fact that, the ideal peak temperature (ie., $348^{0} \mathrm{C}$ which is nearly $81-82 \%$ of the melting temperature of AZ80A Workpiece) has been generated due to the employment of the FSW tool with optimal pin geometry (i.e., taper cylindrical pin geometry). This ideal peak temperature generation have led to superplasticity, which has contributed for plastically deformed material flow in an orderly manner, coupled together with dynamic recyrstallization of the grain structures $[18,23,38,47]$. 

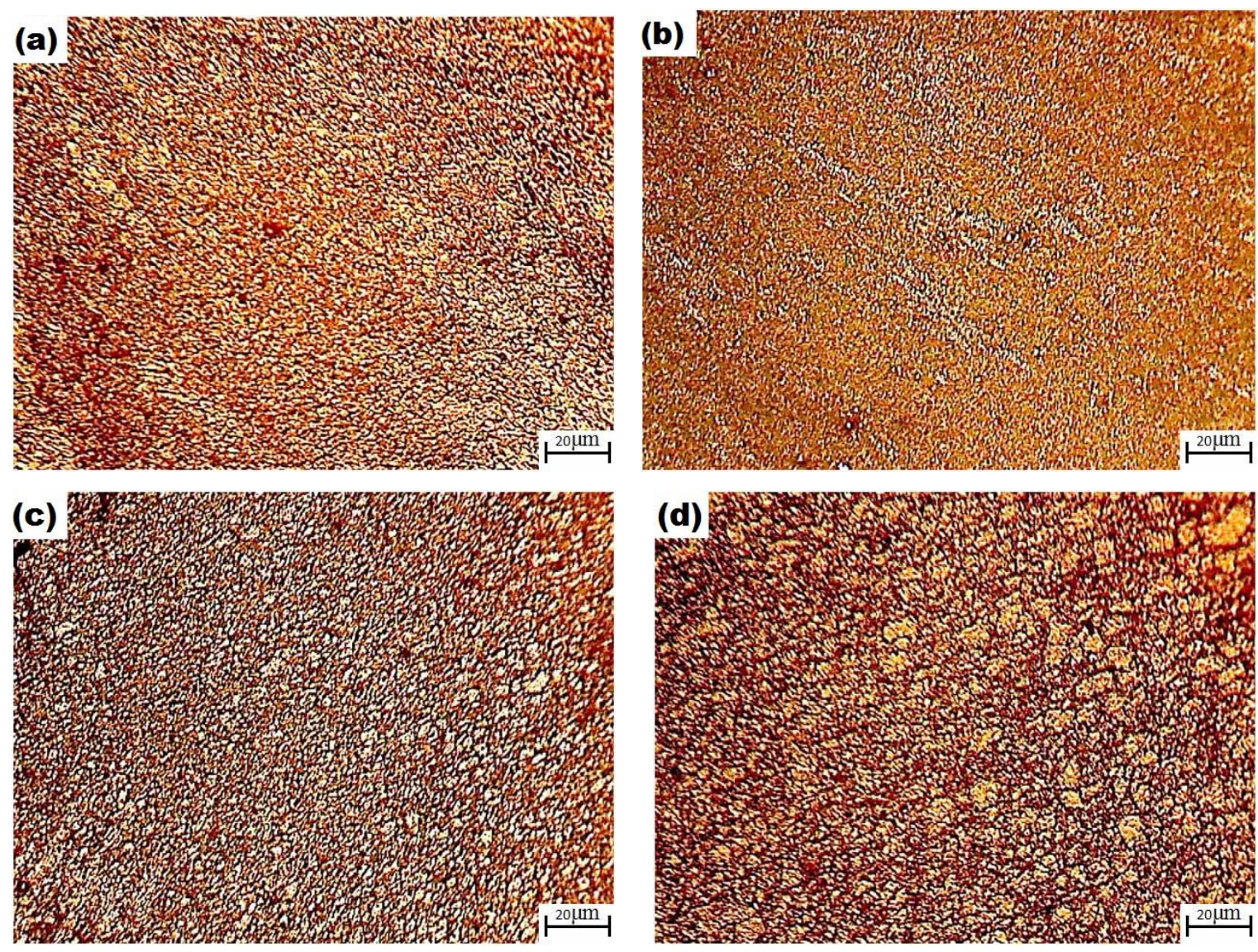

Fig.10. Optical Micrographs of the AZ80A joints fabricated by employing (a) Cylindrical pin geometry

(b) Taper Cylindrical pin geometry (c) Square pin geometry and (d) Triangle pin geometry.

Further detailed examination of these microstructures also helps us to understand that, generation of the peak temperature in ideal volumes plays a crucial part in deciding grain size \& their refinement. For example, the peak temperature generated during the employment of the FSW tool with Triangle Pin geometry is $601 \mathrm{~K}$, which is nearly $75 \%$ of the melting temperature of our investigational workpiece (i.e., AZ80A Mg). But this generated peak temperature is not sufficient $\&$ ideal enough to recrystallize the grain structures into fine grains. At the same time, generation of high levels of peak temperature is also not preferred, as seen in the case of employment of FSW tools with cylindrical pin geometry, which has resulted in the generation of $634 \mathrm{~K}$ peak temperature (i.e., nearly $85 \%$ of the melting temperature of our investigational workpiece). This peak temperature is beyond the ideal level and the size of the refined grains of these welded joints 
are found to be larger in size, in comparison with the size of the grains of the joints fabricated by tool with taper cylindrical pin geometry, where a ideal peak temperature of $621 \mathrm{~K}$ has been obtained. Thus, it can be understood that, the generation of ideal peak temperature plays a momentous part in determining grain size and this refinement of grains are found to have a lineal impact on improving the strength of the fabricated weldments. Bigger the grain size, smaller the mechanical strength of joints, which means that, generation of finely refined small sized grains in centre zone of stir, contributes directly for the increased strength of the FSW joints [51]

\subsection{Interpretation of the SEM images}

The above implicated experimental result, that the employment of tool with taper cylindrical pin geometry have resulted in ideal peak temperature, which have contributed to the fabrication of good quality welded specimen possessing fine sized grains can be further justified by investigating the SEM images of these fabricated welded joint. Figure 11 (a) illustrates us the SEM image of meeting portion of AZ80A Mg alloy \& the region which are dominated by exhilarating action of rotating shoulder of tool. It can be seen that at this junction, the grains have started disintegrating due to the turbulent stirring action of the rotating FSW tool along with the suitable amount of stirring force exerted due to the adoption of ideal amount of axial force and in the zone of stir, the elements of the AZ80A Mg alloy have diffused and the grains seems to be disintegrated completely, due to the dynamic recrystallization process.
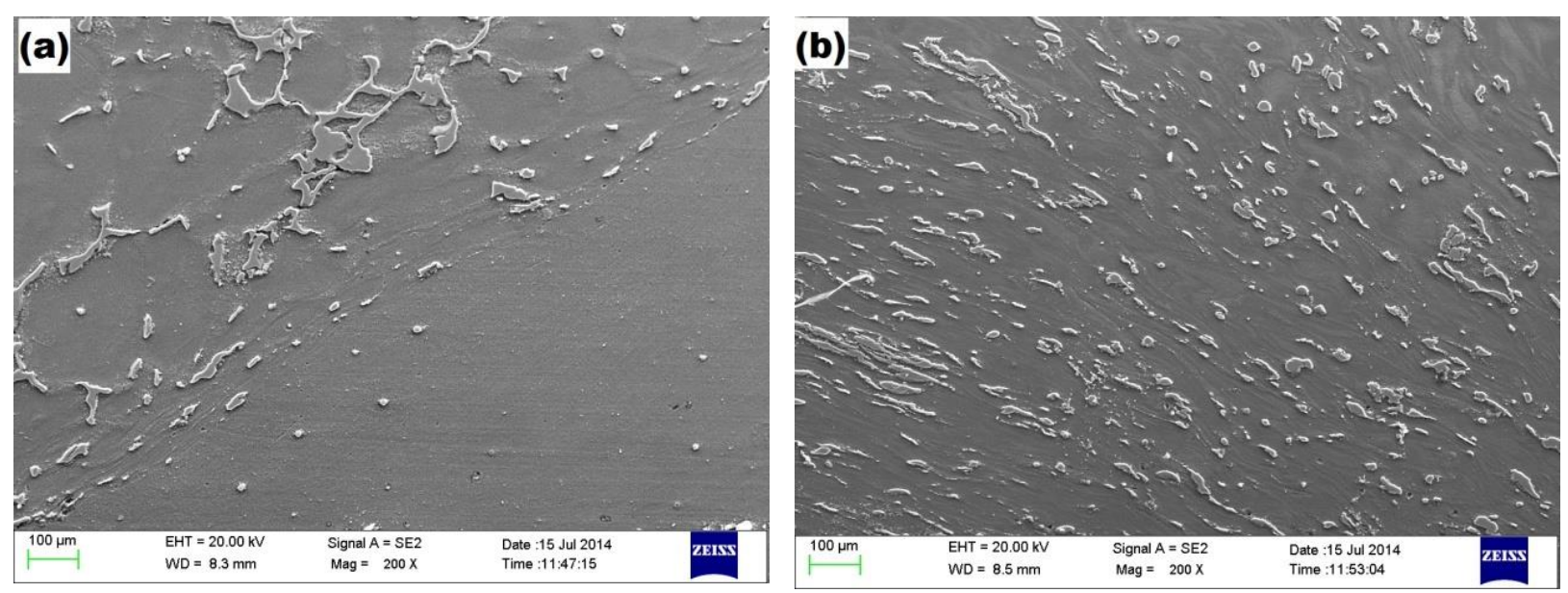


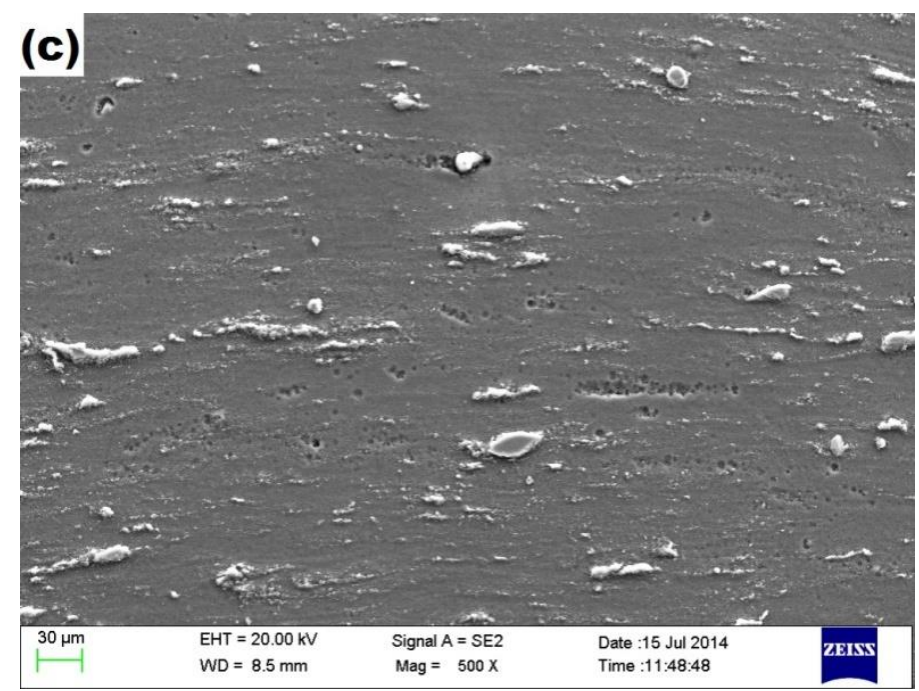

Fig.11. SEM photographs of the (a) junction of the AZ80A Mg \& the region which are dominated by exhilarating action of rotating shoulder of tool (b) thermo mechanically transformed region and (c) centre of the zone of stir

Figure 11 (b) reveals us the generation of peak temperature (in ideal volumes) in the thermo mechanically transformed region, due to which the precipitates were fragmented and the flow of the plasticized materials have been directed along the vertical direction, by the impact of the rotation taper cylindrical pin of the FSW tool. In the Figure 11 (c), which is the centre of the zone of stir, we can observe the existence of the secondary particles of AZ80A Mg alloy, which have dissolved fully, due to the production of peak temperature (in ideal volumes), resulting mainly due to the employment of the FSW tool with taper cylindrical pin geometry

\subsection{Justification from tensile test fractography images}

Examining the manner in which the fracture of the joints fabricated using these tools with four different pin geometries have occurred, will helps us to gain more knowledge and to understand the role of peak temperature in increasing the mechanical strength \& quality of joints. The fractographs of the fractured tensile specimen obtained during the employment of FSW tools with cylindrical, taper cylindrical, square and triangle pin geometries are illustrated in the Figure 12 (a) 
- (d) respectively. Various zones of the SEM fractographic image of the tensile specimen obtained by using FSW tool with triangle pin geometry, i.e., Figure 12 (d), shows the presence of cleavages and improperly deformed grains. This is mainly due to the lack of fusion of the constituents of grain with one another, as the generated peak temperature $(601 \mathrm{~K})$ was not sufficient enough to fuse the grains constituents completely.
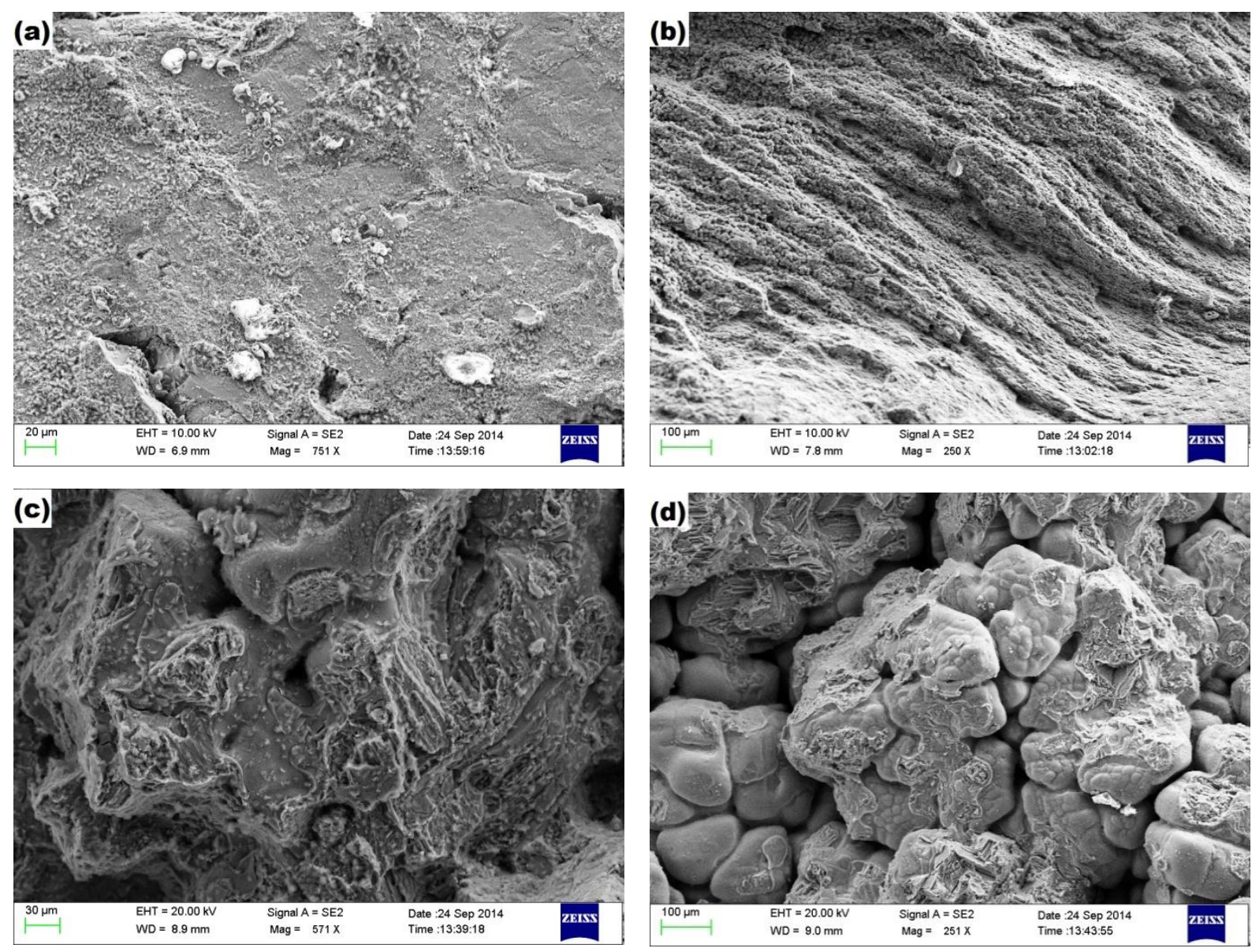

Fig.12. SEM fractographs of the fractured tensile specimen obtained during the employment of FSW tools with (a) cylindrical (b) taper cylindrical (c) square and (d) triangle pin geometries

Similarly, the SEM fractographic image of the tensile specimen obtained by using FSW tool with square pin geometry, i.e., Figure 12 (c), is found to possess large sized inter granular cavity which probably deteriorates the mechanical strength of these joints. The formation of these large sized inter granular cavity in these joints is due to the lack of generation of sufficient amount of peak 
temperature, which could not fuse the grains together. At the same time, the SEM fractographic image of the tensile specimen obtained by using FSW tool with cylindrical pin geometry, i.e., Figure 12 (a), reveals us the fact that, generation of surplus of amount of frictional heat resulting in large peak value temperatures $(634 \mathrm{~K})$ will be able to fuse the grains together, but it will also lead to the formation of voids, large crests $\&$ troughs, which will gradually reduce the mechanical strength of these joints.

And this ideal peak temperature plays a momentous part in improving the mechanical properties of joints, leading to high quality weldments. Further, we can observe that, this tensile specimen has undergone a cone and cup fracture mode. This mode of fracture takes place only when the joints have experienced uniform flow of plasticized material in their centre zone of nugget and uniform flow of plasticized material during FSW happens whenever the nugget zone is defect free [5254]. Thus, it can be inferred that, the peak temperature generated $(621 \mathrm{~K}$, nearly $81-82 \%$ of the melting temperature of employed workpiece) in the time of employment of tool with taper cylindrical pin geometry is ideal enough to fabricate high quality AZ80A Mg weldments

\section{CONCLUSIONS}

In FSW technique, the geometry of pin of employed tool plays a momentous part in influencing the plasticized material flow, temperature generation, grain refinement, mechanical properties of fabricated joints etc. For better \& perfect understanding of the FSW process, especially w.r.t to the tool temperatures \& flow of heat, there exist the need of employing both mathematically developed simulation models and real experimentation methods. Majority of the previously carried out experimental research works have concentrated their research towards the measurement of the temperature over distinct \& limited regions of the workpiece surface, there exists a vital \& unavoidable need for analysing \& understanding the temperatures, flow of generated around the FSW tool pin profile, to derive a mathematical model to predict the flow of temperature for various 
FSW tool pin profiles, the role of the geometrical design of the various pin profiles in regulating the flow of generated frictional heat and to compare these model results with that of the actual experimental data. Based on these aspects, this experimental research focuses to investigate the reasons behind generation of varying temperature values during the employment of tools with different pin geometries, leading to variations in microstructural characterisation and properties of the fabricated joints. In this research, an thermo mechanical process model was formulated to estimate and determine the values of peak temperatures generated during the employment of tools with four distinct pin geometries (including cylindrical, taper cylindrical, square and triangle) for welding AZ80A $\mathrm{Mg}$, to understand their indicative part in influencing the grain size, their mechanical strength and quality of the joints. The generated numerical values are compared with that of the actual experimental values and the following results were inferred:

- A thermo mechanical process model was formulated successfully and the numerically simulated temperature distribution clearly illustrates the variation in temperature on the workpiece, tool pin contact area, shoulder area and tool pin region.

- The percentage difference between the experimental and mathematical model simulation values obtained for the maximum temperature are $1.42 \%, 0.96 \%, 1.18 \%$ and $0.98 \%$ respectively for FSW tools with cylindrical, taper cylindrical, square and triangle pin geometries.

- FSW tool with triangular pin geometry generated minimum value of peak temperature (601 $\mathrm{K})$ and maximum peak temperature $(634 \mathrm{~K})$ was found to be generated by cylindrical pin.

- Taper cylindrical pin generated $621 \mathrm{~K}$ peak temperature which is nearly $81-82 \%$ of the melting temperature of the material of investigation, i.e., AZ80A $\mathrm{Mg}$ and square pin generated a peak temperature of $608 \mathrm{~K}$. 
- The joints obtained by employing tool with taper cylindrical pin geometry was found to possess very exceptional sized grains, distributed consistently \& homogenously, in comparison with remaining three welded joint's microstructures.

- The discrepancies of the anticipated values from that of the real experiential outcomes are within $\pm 1 \%$, which reveals us that, the established mathematical model is very much fit to the actual experimental results. Moreover, the established quadratic regression model was found not to be over fitted and it is evident that, only less than $1-2$ per cent of the total variations are not interpreted by this model.

- Seven AZ80A Mg joints were obtained using the optimized input parameters of FSW technique. All the seven weldments were found to be absolutely defect free and the tensile strength of these seven joints were found to be in the range of $245 \mathrm{MPa}$ to $249 \mathrm{Mpa}$, which exhibits that their exquisite compliance with the predicted values.

\section{REFERENCES}

1. Kulwant Singh, Gurbhinder Singh and Harmeet Singh. 2018. Review on friction stir welding of magnesium alloys. Journal of Magnesium and Alloys, 6(4): 399-416. https://doi.org/10.1016/j.jma.2018.06.001

2. Shah, L.H., Othman N,H. and Gerlich, A. 2017. Review of research progress on aluminium-magnesium dissimilar friction stir welding. Science and Technology of Welding and Joining, 23(3): 256-270. https://doi.org/10.1080/13621718.2017.1370193

3. Sevvel, P. and Satheesh, C. 2019. Role of tool rotational speed in influencing microstructural evolution, residual-stress formation and tensile properties of friction-stir welded AZ80A Mg alloy. Materiali in Tehnologije, 52 (5): 607-614. https://doi.org/10.17222/mit.2017.213

4. Jaiganesh, V. and Sevvel, P. 2014. Effect of Process Parameters during Friction Stir Welding of Al 6063 Alloy. Advanced Materials Research, 984: 604-607. https://doi.org/10.4028/www.scientific. net/AMR.984-985.604 
5. Feng, Z., Wang, W.L., David, S.A. and Sklad, P.S. 2007. Modelling of residual stresses and property distributions in friction stir welds of aluminium alloy 6061-T6. Science and Technology of Welding and Joining, 12(4): 348-356. https://doi.org/10.1179/174329307X197610

6. Rafiei, R., Ostovari Moghaddam, A., Hatami, M.R., Khodabakhshi, F., Abdolahzadeh, F.A. and Shokuhfar, A. 2016. Microstructural characteristics and mechanical properties of the dissimilar friction-stir butt welds between an Al-Mg alloy and A316L stainless steel. International Journal of Advanced Manufacturing Technology, 90: 2785-801. https://doi.org/10.1007/s00170-016-9597-X

7. Thangaiah Stephan, I.S., Sevvel, P., Satheesh, C., Jaiganesh, V. 2017. Investigation on the impingement of parameters of FSW process on the microstructural evolution and mechanical properties of AZ80A Mg alloy joints. FME Transactions, 46 (1): 23-32, https://doi.org/10.5937/fmet1801023T

8. Girard, M., Huneau, B., Genevois, C. Sauvage, X. And Racineux, G. 2010. Friction stir diffusion bonding of dissimilar metals. Science and Technology of Welding and Joining, 15(8): 661-665. https://doi.org/10.1179/136217110X12720264008475

9. Padmanaban, R., Ratna Kishore, V. and Balusamy, V. 2014. Numerical Simulation of Temperature Distribution and Material Flow During Friction Stir Welding of Dissimilar Aluminum $\quad$ Alloys. $\quad$ Procedia $\quad$ Engineering, 854-863. https://doi.org/10.1016/j.proeng.2014.12.360

10. Sevvel, P., Satheesh, C., Jaiganesh, V. 2018. Influence of tool rotational speed on microstructural characteristics of dissimilar $\mathrm{Mg}$ alloys during friction stir welding. Transactions of the Canadian Society for Mechanical Engineering, 43(1): 132-141, https://doi.org/10.1139/tcsme-2018-0037

11. Stephan Thangaiah, I.S., Sevvel, P., Satheesh, C., Mahadevan, S. 2018.Experimental Study on the Role of Tool Geometry in Determining the Strength \& Soundness of Wrought AZ80A Mg Alloy Joints During FSW Process, 46(4): 612-622. https://doi.org/10.5937/fmet1804612T

12. Xiong, J.T., Li, J.L., Qian, J.W. and Huang, W.D. 2012. High strength lap joint of aluminium and stainless steels fabricated by friction stir welding with cutting pin. Science and Technology of Welding and Joining, 17(3):196-201. https://doi.org/10.1179/1362171811Y.0000000093 
13. Meng, X., Jin, Y., Ji, S., Yan, D. 2018. Improving friction stir weldability of Al/Mg alloys via ultrasonically diminishing pin adhesion. Journal of Materials Science and Technology, 34 (10), 1817-1822, https://doi.org/10.1016/j.jmst.2018.02.022.

14. Xun Liu, Gaoqiang Chen, Jun Ni and Zhili Feng. 2017. Computational fluid dynamics modeling on steady-state friction stir welding of aluminum alloy 6061 to TRIP steel. Journal of Manufacturing Science and Engineering, 139(5):051004. https://doi.org/10.1115/1.4034895

15. Ram Kumar, S., Duraiselvam, M., Sevvel, P. (2020). Acoustic emission based deep learning technique to predict adhesive bond strength of laser processed CFRP composites. FME Transactions, 48(3), 611-619, https://doi.org/10.5937/fme2003611S

16. Richmire, S., Hall, K., Haghshenas, M. 2018. Design of experiment study on hardness variations in friction stir welding of AM60 Mg alloy. Journal of Magnesium and Alloys, 6 (3) 215-228, https://doi.org/10.1016/j.jma.2018.07.002.

17. Bobby Kannan, M., Dietzel, W., Zeng, R., Zettler R. And dos Santos, J.F. 2007. A study on the SCC susceptibility of friction stir welded AZ31 Mg sheet. Material Science and Engineering: A, 460 - 462: 243-250. https://doi.org/10.1016/j.msea.2007.01.065

18. Sevvel, P., Dhanesh Babu, S.D., Senthil Kumar, R. 2020. Peak temperature correlation and temperature distribution during joining of AZ80A Mg alloy by FSW - A numerical and experimental investigation. Strojniški vestnik - Journal of Mechanical Engineering, 66 (6),395-407, https://doi.org/10.5545/sv-jme.2020.6566.

19. Elyasi, M., Derazkola,, H.A.Hosseinzadeh, M. 2016. Investigations of tool tilt angle on properties friction stir welding of A441 AISI to AA1100 aluminium. Proceedings of the Institution of Mechanical Engineers, Part B: Journal of Engineering Manufacture, 230 (7), 1234-1241, https://doi.org/10.1177/0954405416645986.

20. Pengliang Niu, Wenya Li, Xiawei Yang and Achillefs Vairis. 2017. Effects of microstructural asymmetries across friction stir welded AA2024 joints on mechanical properties. Science and Technology of Welding and Joining, 23(1): 58-62. https://doi.org/10.1080/ 13621718.2017.1328765

21. Prakash Kumar Sahu and Sukhomay Pal. 2017. Influence of metallic foil alloying by FSW process on mechanical properties and metallurgical characterization of AM20 Mg alloy. Materials Science and Engineering: A, 684: 442-455. https://doi.org/10.1016/j.msea.2016.12.081 
22. Sevvel, P., Satheesh, C., Senthil Kumar, R. 2019. Generation of regression models and multi-response optimization of friction stir welding technique parameters during the fabrication of AZ80A Mg alloy joints. Transactions of the Canadian Society for Mechanical Engineering, 44 (2): 311-324, https://doi.org/10.1139/tcsme-2019-0162.

23. Dhanesh Babu, S.D., Sevvel, P., Senthil Kumar, R. 2020. Simulation of heat transfer and analysis of impact of tool pin geometry and tool speed during friction stir welding of AZ80A Mg alloy plates. Journal of Mechanical Science and Technology, 34: 4239-4250, https://doi.org/10.1007/s12206-020-0916-7.

24. Xiawei Yang, Wuyuan Feng, Wenya Li, Yaxin Xu, Qiang Chu, Tiejun Ma and Weibing Wang. 2018. Numerical modelling and experimental investigation of thermal and material flow in probeless friction stir spot welding process of Al 2198-T8. Science and Technology of Welding and Joining, 23 (8): 704-714. https://doi.org/10.1080/13621718.2018.1469832

25. Wenxiao Pan, Dongsheng Li, Alexandre M.Tartakovsky, Said Ahzi, Marwan Khraisheh and Moe Khaleel. 2013. A new smoothed particle hydrodynamics non-Newtonian model for friction stir welding: Process modeling and simulation of microstructure evolution in a magnesium alloy. International Journal of Plasticity, 48: 189-204. https://doi.org/10.1016/j.ijplas.2013.02.013

26. Giridharan, K., Sevvel, P., Senthilnathan, K., Muthukumaran, S., Padmanabhan, S. 2019. Experimental study on mechanical properties of friction stir welded dissimilar joints of aluminiumalloys AA8011-AA6082. International Journal of Vehicle Structures and Systems, 11 (2), 135-139, https://doi.org/10.4273/ijvss.11.2.04.

27. Colegrove, P.A., Shercliff, H.R. and Zettler, R. 2007. Model for predicting heat generation and temperature in friction stir welding from the material properties. Science and Technology of Welding and Joining, 12 (4); 284-297. https://doi.org/10.1179/174329307X197539

28. Devaiah, D., Kishore, K. and Laxminarayana, P. 2018. Optimal FSW process parameters for dissimilar aluminium alloys (AA5083 and AA6061) Using Taguchi Technique. Materials Today $\quad$ Proceedings, 5(2): 4607-4614. https://doi.org/10.1016/j.matpr.2017.12.031

29. Sevvel, P., Srinivasan, D., Balaji, AJ., Gowtham, N., KalyanaVaradhan, V.G., Kumaresh, P., Kishore Bajrang, M. 2019. Design \& fabrication of innovative desktop 3D printing 
machine. Materials Today: Proceedings, $22 \quad$ (4): 3240-3249, https://doi.org/10.1016/j.matpr.2020.03.284.

30. Muthu Krishnan, M., Maniraj, J., Deepak, R. and Anganan, K. 2018. Prediction of optimum welding parameters for FSW of aluminium alloys AA6063 and A319 using RSM and ANN. Materials Today Proceedings, 5(1): 716-723. https://doi.org/10.1016/j.matpr.2017.11.138

31. Kesharwani, R.K., Panda, S.K., Pal, S.K. 2014. Multi-objective optimization of friction stir welding parameters for joining of two dissimilar thin aluminum sheets. Procedia Materials Science, 6: 178-187, https://doi.org/10.1016/j.mspro.2014.07.022.

32. Gok, K. and Aydin, M. 2013. Investigations of friction stir welding process using finite element method. International Journal of Advanced Manufacturing Technology, 68 (1-4): 775-780. https://doi.org/10.1007/s00170-013-4798-Z

33. Mohammad, R. and Hamidreza, N. 2011. Analysis of transient temperature and residual thermal stresses in friction stir welding of aluminium alloy 6061-T6 via numerical simulation. International Journal of Advanced Manufacturing Technology, 55:143-152. https://doi.org/10.1007/s00170-010-3038-z

34. Hasan, A., Bennett, C.J. and Shipway, P.H. 2015. A numerical comparison of the flow behaviour in Friction Stir Welding (FSW) using unworn and worn tool geometries. Materials \& Design, 87: 1037-1046. https://doi.org/10.1016/j.matdes.2015.08.016

35. Sevvel, P., Stephan Thangaiah, I.S., Mars Mukesh, S., Mohammed Anif, G. 2015. Laboratory Scale Testing of Thermoelectric Regenerative Braking System. International Journal of Vehicle Structures \& Systems. 7 (4), 157-160, http://dx.doi.org/10.4273/ijvss.7.4.08

36. Hou, L., Yu, J., Zhang, D., Zhuang. L., Zhou, L., Zhang. J. 2017. Corrosion behavior of friction stir welded Al-Mg-(Zn) alloys. Rare Metal Materials and Engineering, 46 (9): 2437-2444, https://doi.org/10.1016/S1875-5372(17)30212-6

37. Derazkola, H.A., Khodabakhshi, F. and Simchi, A. 2017. Friction-stir lap-joining of aluminium-magnesium/poly-methyl-methacrylate hybrid structures: thermo-mechanical modelling and experimental feasibility study. Science and Technology of Welding and Joining, 23(1): 35-49. https://doi.org/10.1080/13621718.2017.1323441

38. Sevvel, P., Mahadevan, S., Satheesh, C., Srinivasan, D., Jaiganesh, V. 2019. Experimental Investigation on the Improvement of the Properties of the AZ80A Mg Alloy Joints Using 
Friction Stir Welding process. FME Transactions, 47 (3): 452-463. https://doi.org/10.5937/fmet1903452S

39. Wenya Li, Zhihan Zhang, Jinglong Li and Chao, Y.J. 2012. Numerical analysis of joint temperature evolution during friction stir welding based on sticking contact. Journal of Materials Engineering and Performance, 21(9): 1849-1856. https://doi.org/10.1007/s11665011-0092-0

40. Chen, C.M., Kovacevic, R. 2003. Finite element modeling of friction stir welding - thermal and thermomechanical analysis. International Journal of Machine Tools and Manufacture, 43 (13): 1319-1326. https://doi.org/10.1016/S0890-6955(03)00158-5.

41. Nandan, R., Roy, G.G. and Debroy, T. 2006. Numerical simulation of three-dimensional heat transfer and plastic flow during friction stir welding. Metallurgical and Materials Transactions A, 37 (4): 1247-1259. https://doi.org/10.1007/s11661-006-1076-9

42. Soundararajan, V., Zekovic, S. and Kovacevic, R. 2005. Thermo-mechanical model with adaptive boundary conditions for friction stir welding of Al 6061. International Journal of Machine Tools and Manufacture, 45 (14), 1577-1587. https://doi.org/10.1016/j.ijmachtools.2005.02.008

43. Basim, M.A., Al Bhadle, Rafat, A.A., Al Azzawi, Thornton, R., Beamish, K., Shi, S. And Dong, H.B. 2018. Equations of heat generation during friction stir welding for tapered polygonal tools. Science and Technology of Welding and Joining, 24(5):1-8. https://doi.org/10.1080/13621718.2018.1495407

44. Satheesh, C., Sevvel, P., Senthil Kumar, R. 2020. Experimental Identification of Optimized Process Parameters for FSW of AZ91C Mg Alloy Using Quadratic Regression Models. Strojniški vestnik - Journal of Mechanical Engineering, 66 (12): 736-751, https://doi.org/10.5545/sv-jme.2020.6566.

45. Jinwen Qian, Yan Ou, Jinglong Li, Yifeng Xiao, Liang Wu and Yanfei Xu. 2017. An analytical model to calculate the peak temperature for friction stir welding, Science and Technology of Welding and Joining, 22 (6): 520-525. https://doi.org/10.1080/13621718.2016.1268367

46. Weijun He, Li Zheng, Renlong Xin and Qing Liu. 2017. Microstructure-based modeling of tensile deformation of a friction stir welded AZ31 Mg alloy. Material Science and Engineering: A, 687: 63-72. https://doi.org/10.1016/j.msea.2017.01.053 
47. Sevvel, P., Jaiganesh, V. 2017. Influence of the arrangement of materials and microstructural analysis during FSW of AZ80A \& AZ91C Mg alloys. Archives of Metallurgy and Materials, 62 (3): 1795-1801. https://doi.org/0.1515/amm-2017-027

48. Shi, B., Peng, Y. and Pan, F. 2015. A generalized thermodynamically consistent distortional hardening model for Mg alloys. International Journal of Plasticity, 74: 158174. https://doi.org/ 10.1016/j.ijplas.2015.06.01

49. Xiong, J.T. Li, J.L., Wei, Y.N., Zhang, F.S. and Huang, W.D. 2013. An analytical model of steady-state continuous drive friction welding. Acta Materialia; 61 (5): 1662-1675. https://doi.org/ 10.1016/j.actamat.2012.11.042

50. Nan Xu, Qining Song, Hidetoshi Fujii, Yefeng Bao and Jun Shen. 2018. Mechanical properties' modification of large load friction stir welded AZ31B Mg alloy joint. Materials Letters, 219: 93-96. https://doi.org/10.1016/j.matlet.2018.02.099

51. Jaignaesh, V., Sevvel, P. 2014. Effect of Process Parameters during Friction Stir Welding of Al 6063 Alloy. Advanced Materials Research, 984: 604-607. https://doi.org/10.4028/www.scientific.net/AMR.984-985.604

52. Coelho, R.S., Kostka, A., dos Santos J.F. and Kaysser-Pyzalla, A. 2012. Friction-stir dissimilar welding of aluminium alloy to high strength steels: Mechanical properties and their relation to microstructure. Materials Science and Engineering: A, 556: 175-183. https://doi.org/10.1016/j.msea.2012.06.076.

53. Seyed Alireza Askariani, Hassan Pishbin and Mahdi Moshref-Javadi. 2017. Effect of welding parameters on the microstructure and mechanical properties of the friction stir welded joints of a Mg-12Li-1Al alloy. Journal of Alloys and Compounds, 724 (15): 859868. https://doi.org/10.1016/ j.jallcom. 2017.07.071

54. William Yi Wang, Shun Li Shang, Yi Wang, Zhi-Gnag Mei, Kristopher A. Darling, Laszlo J. Kecskes, Suveen N. Mathaudhu, Xi Dong Hui and Zi-Kui Liu. 2014. Effects of alloying elements on stacking fault energies and electronic structures of binary Mg alloys: A firstprinciples study. Materials Research Letters, 2(1): 29-36. https://doi.org/10.1080/21663831.2013.858085 
Figures
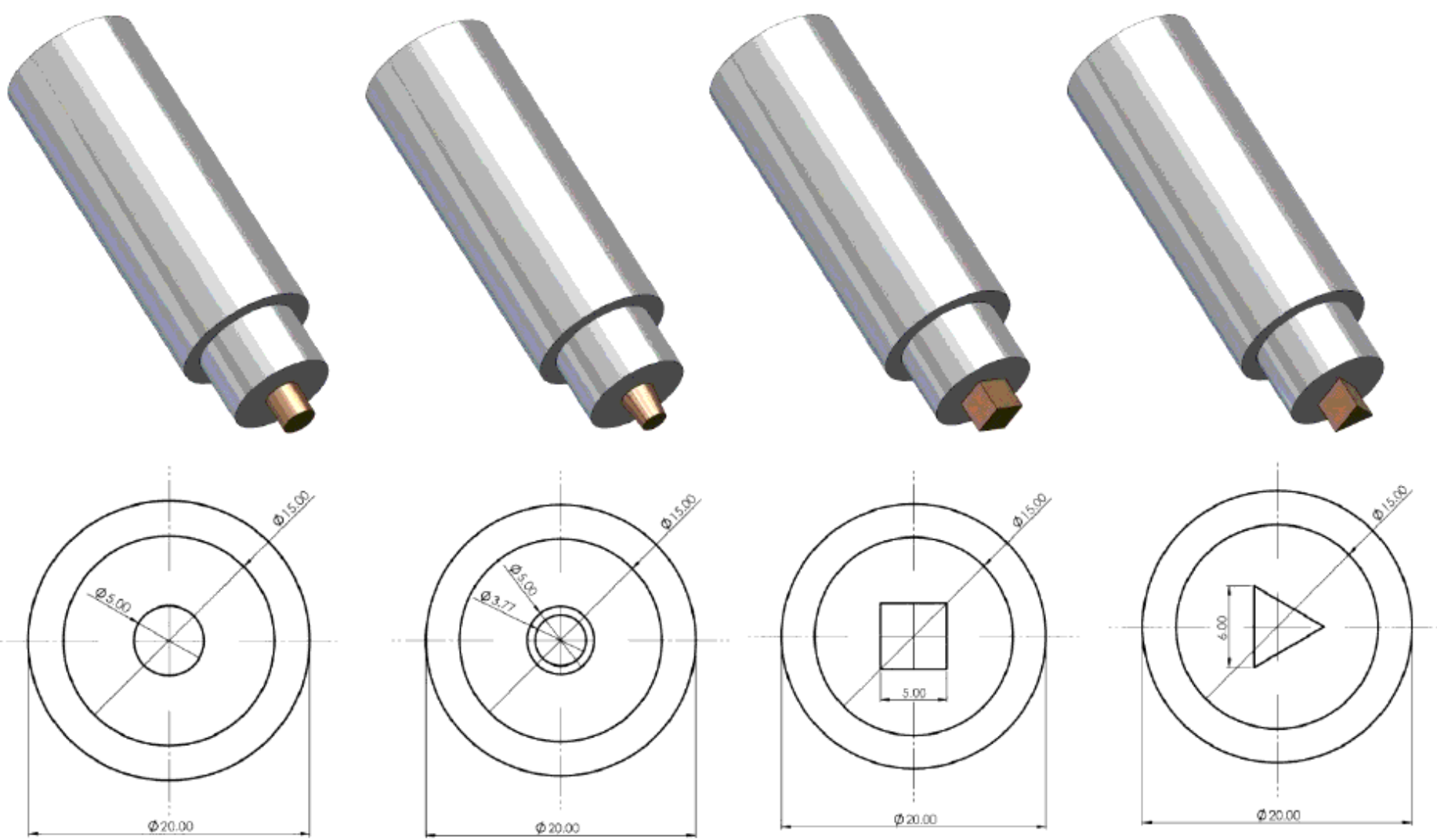

Cylindrical Pin Geometry

Taper Cylindrical Pin Geometry
Square Pin Geometry
Triangular Pin Geometry

Figure 1

Diagrammatic representation of the FSW tools with four different pin geometries employed in this investigation. 
Workpiece Plate 1

(Magnesium Alloy AZ80A)
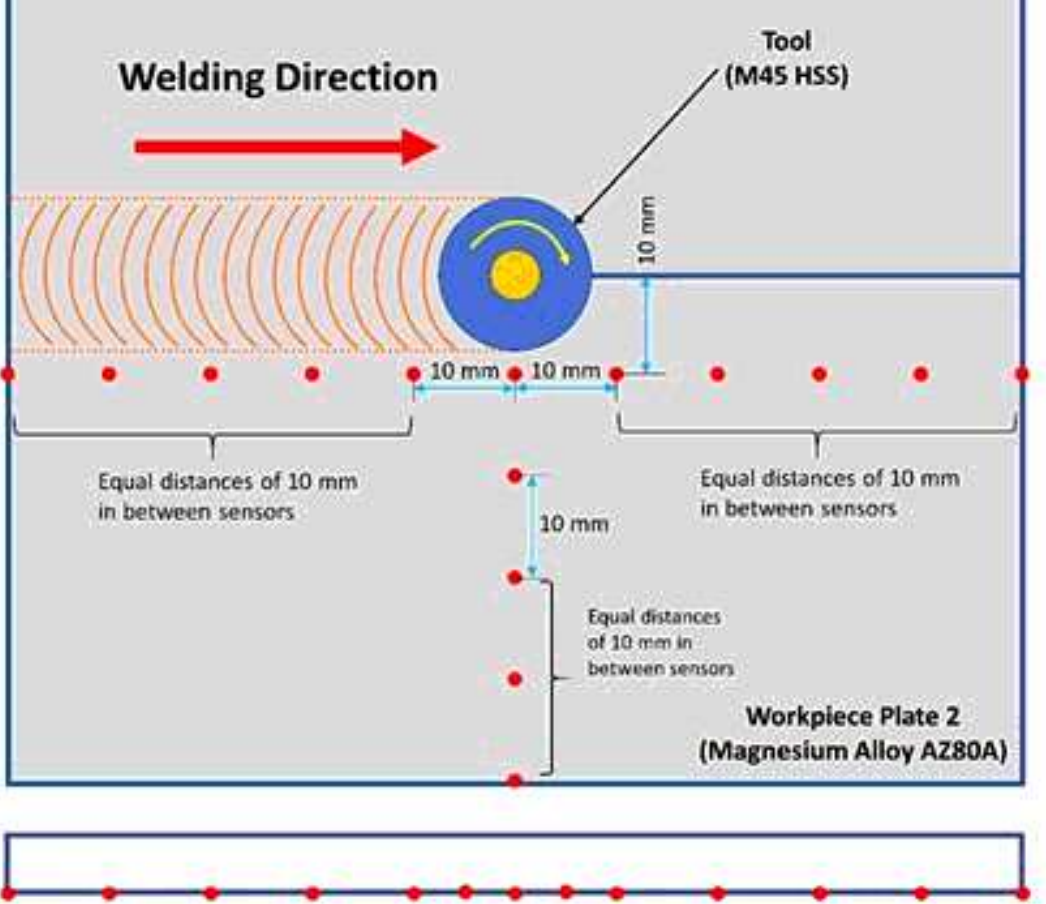

Centre line

bottom side sensors

\section{Figure 2}

Schematic arrangement \& location of the employed thermocouples on various regions of the AZ80A Mg alloy flat plates 


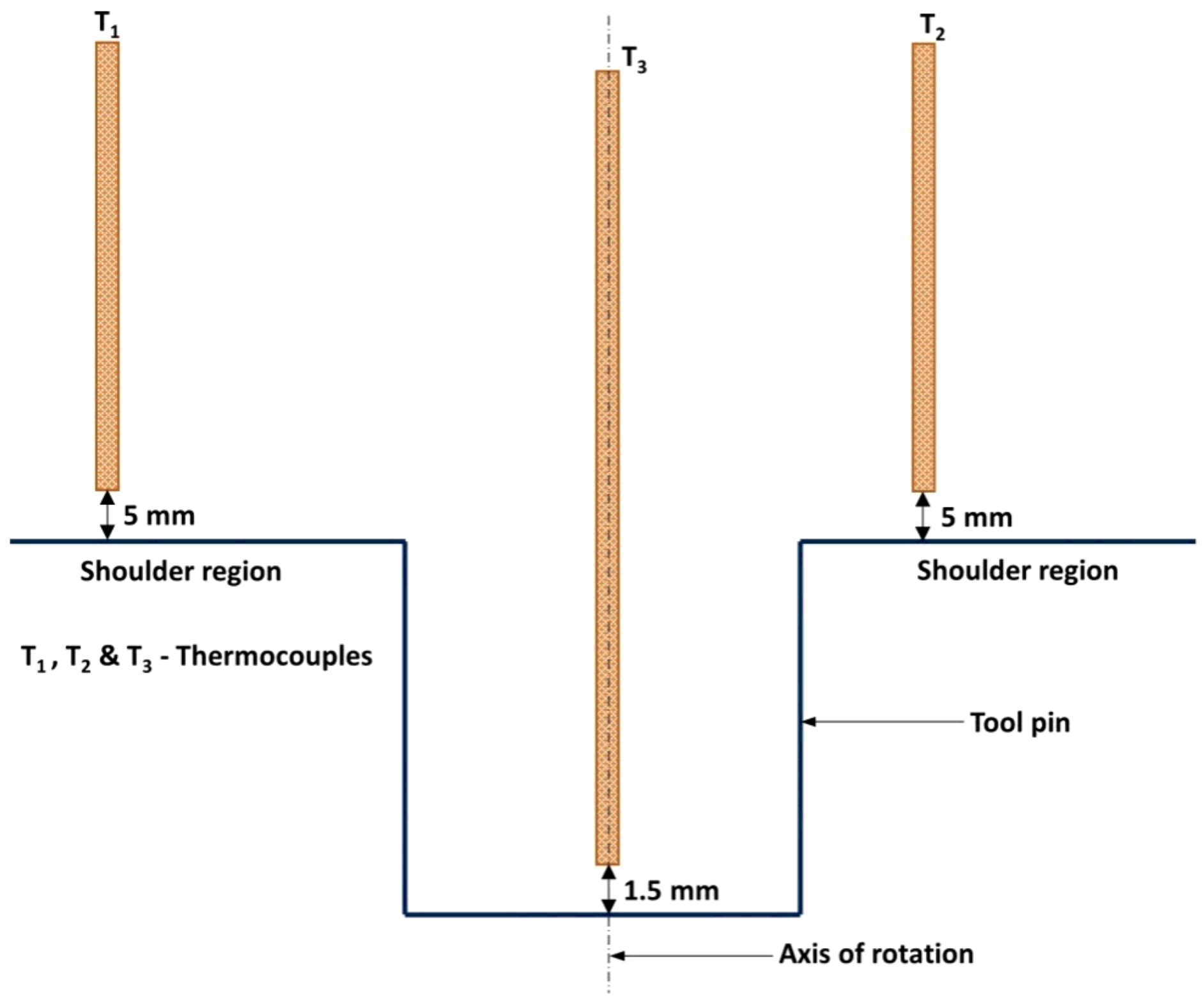

Figure 3

Cross Sectional graphical illustration of the arrangements of the thermocouples in the interior regions of the employed FSW tools 


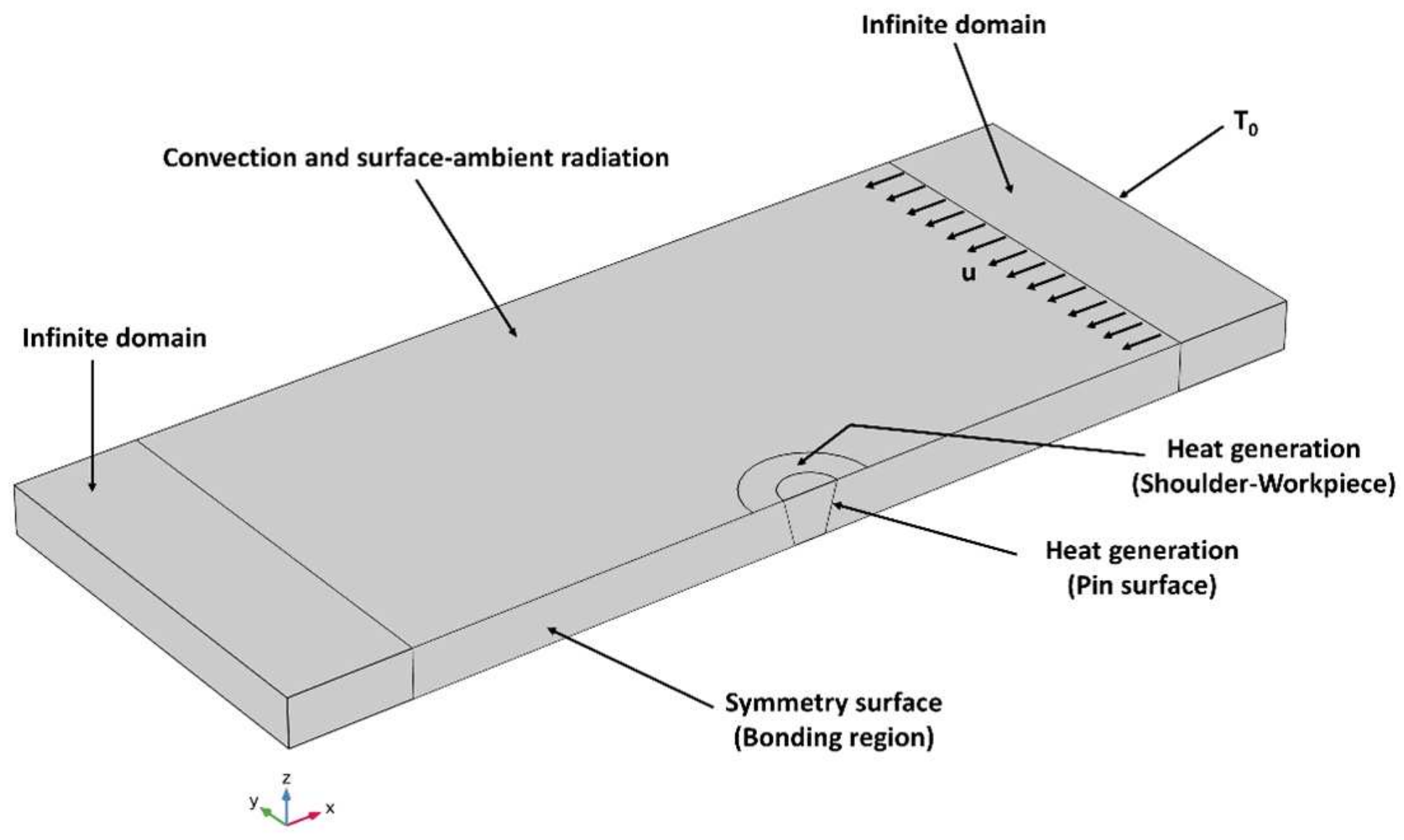

Figure 4

Diagrammatic view of the formulated geometry of process model for joining of AZ80A Mg by FSW technique 


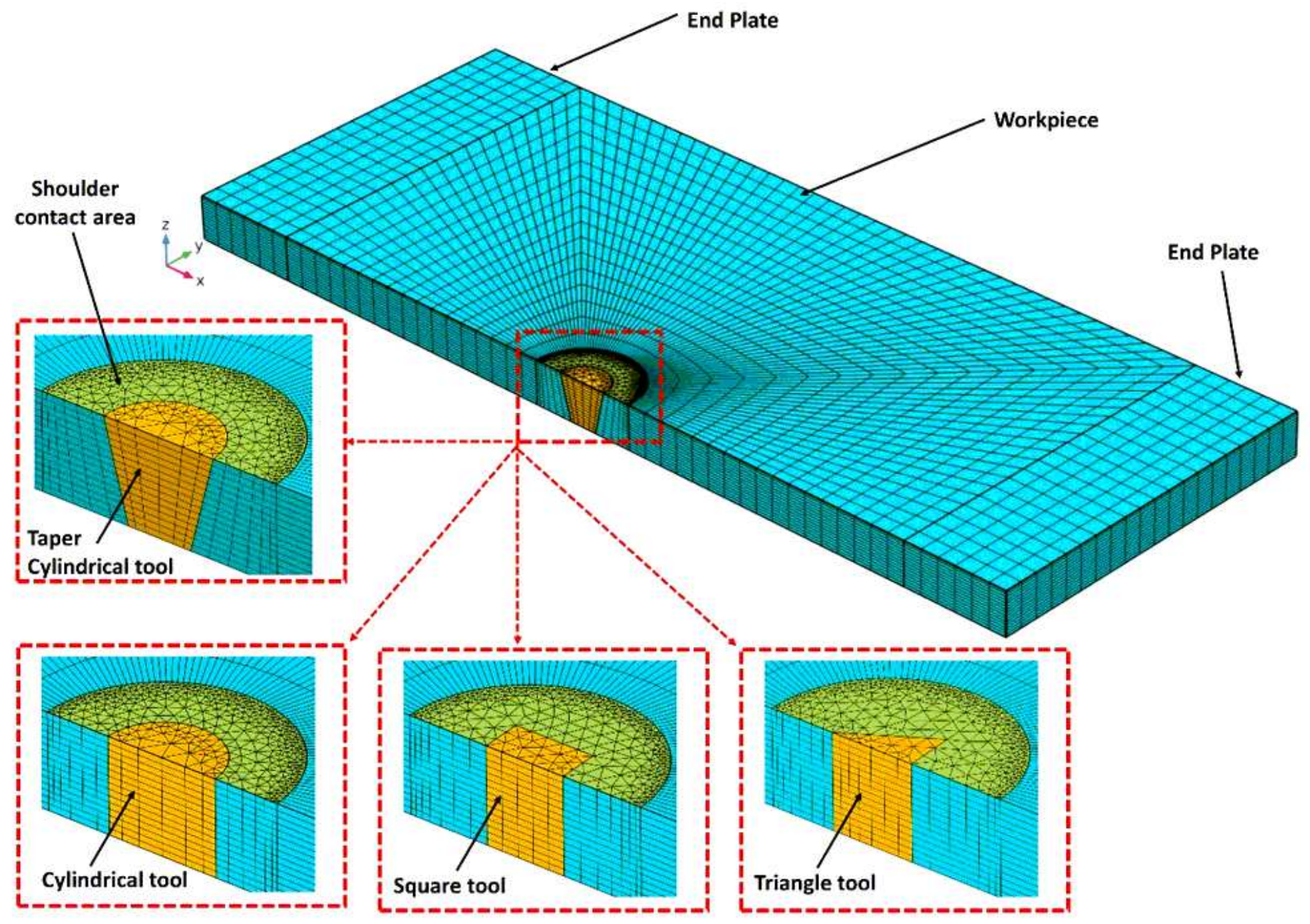

\section{Figure 5}

Graphical representation of the position of the countless, infinite nodes of grid placed around the entire circumferential region of the different pin geometries 


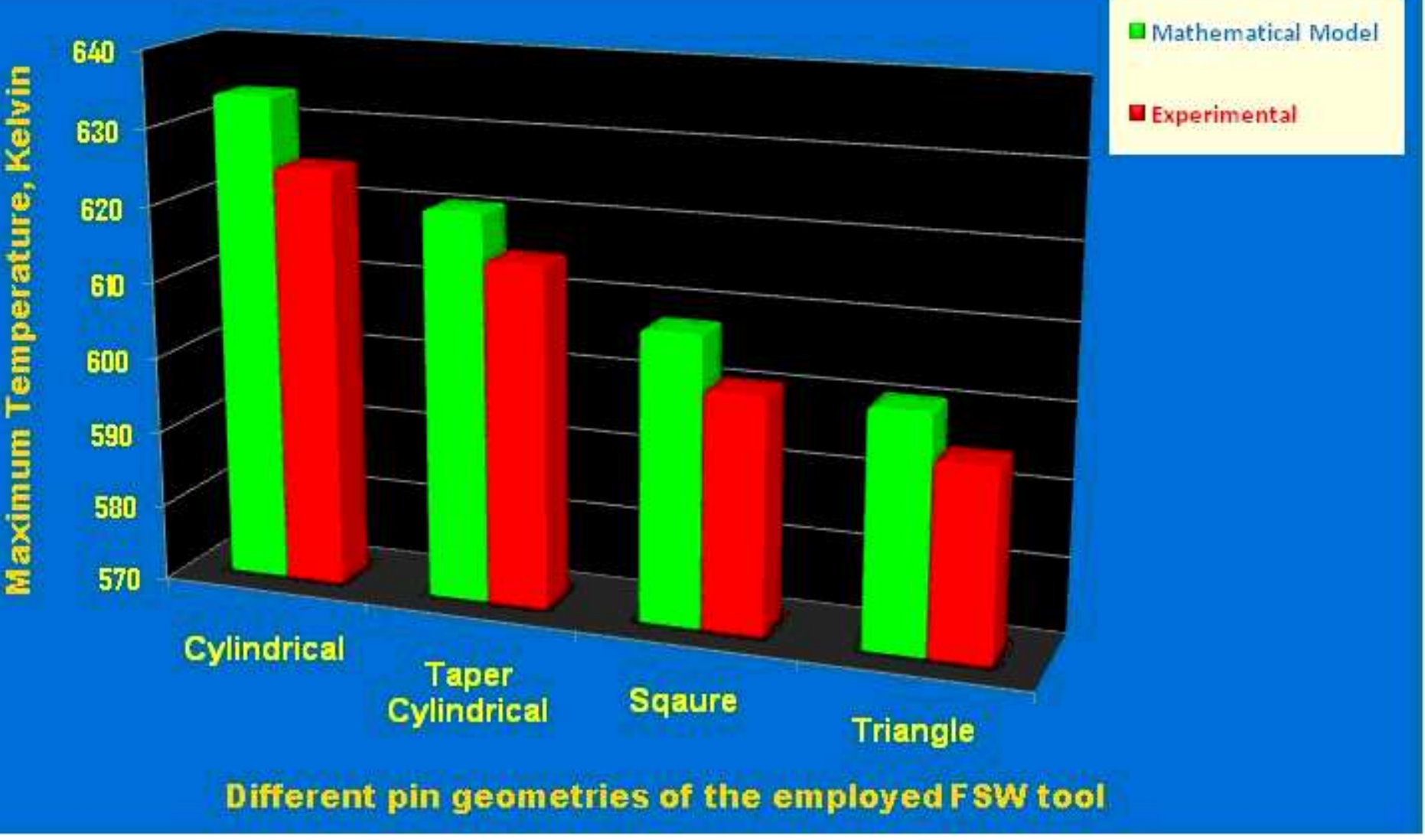

\section{Figure 6}

Graphical comparison of the differences in peak temperatures between the actual experimental values and the mathematical model simulation values
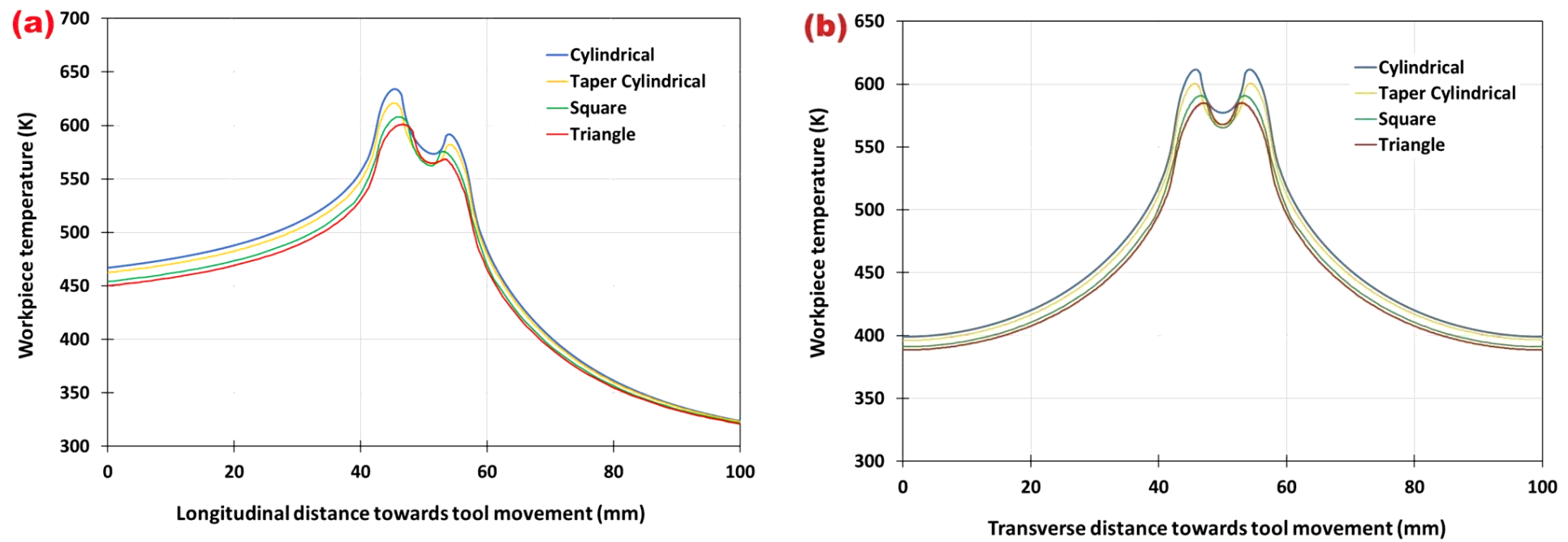

\section{Figure 7}

Graphical comparison of the Variations in temperature (a) along the longitudinal axis and its offset and (b) along the transverse axis behind tool movement and its offset. 


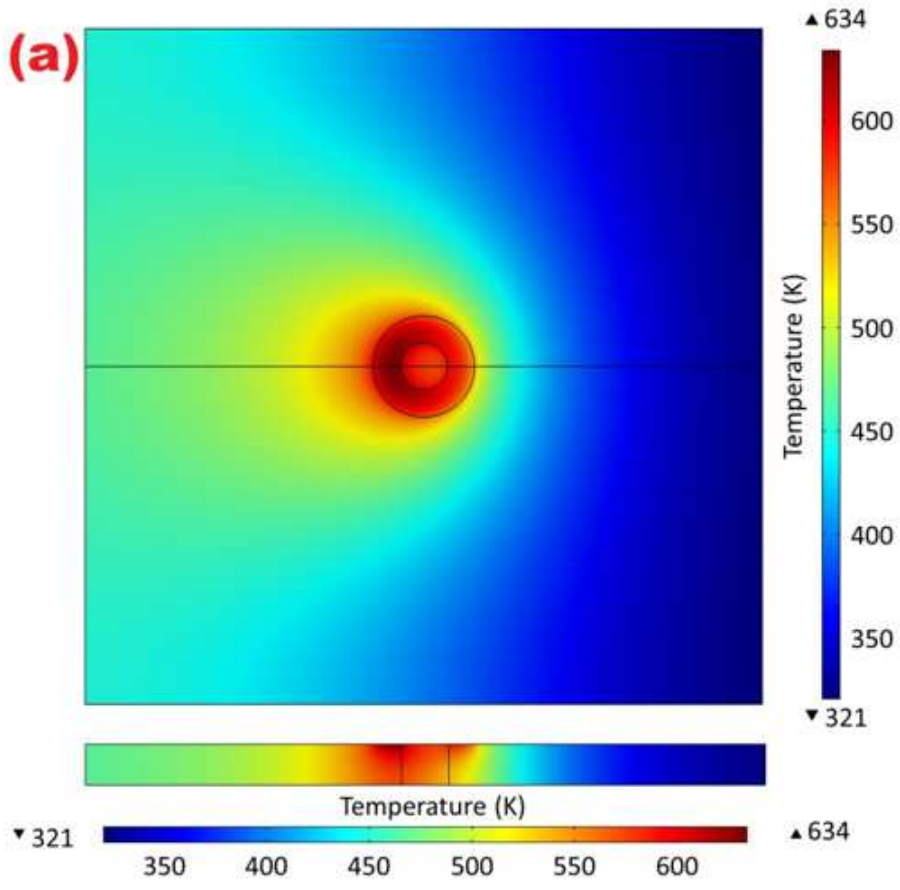

\section{Cylindrical pin}

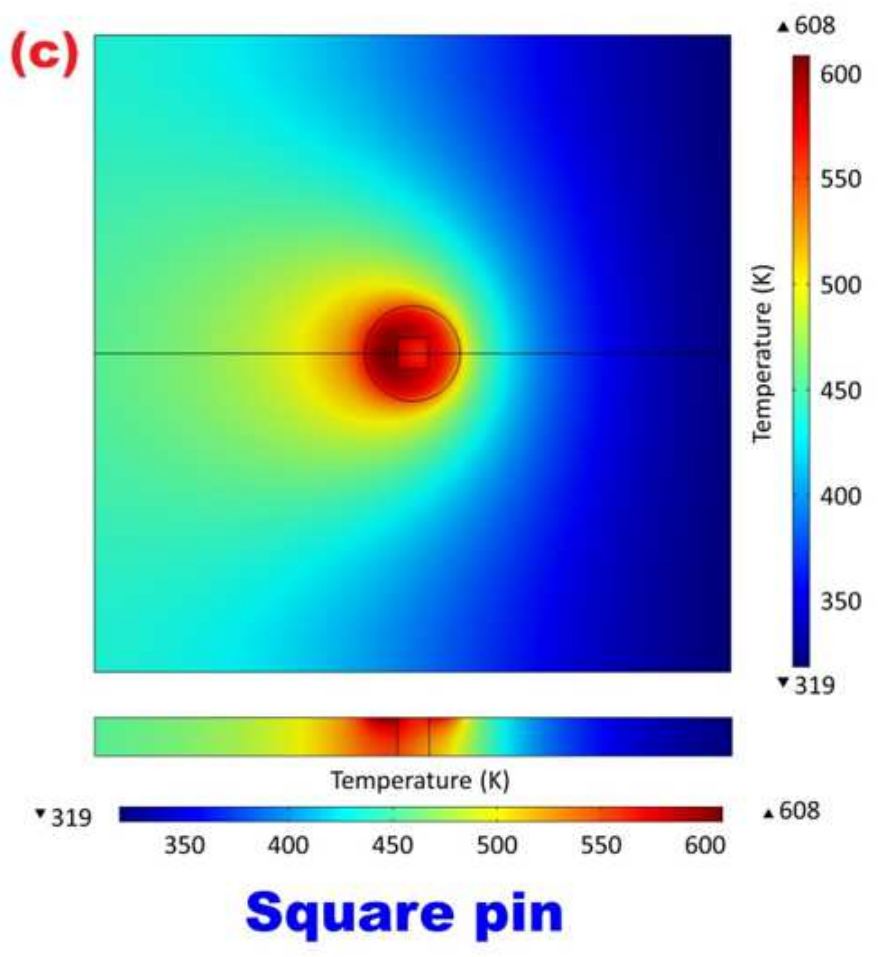

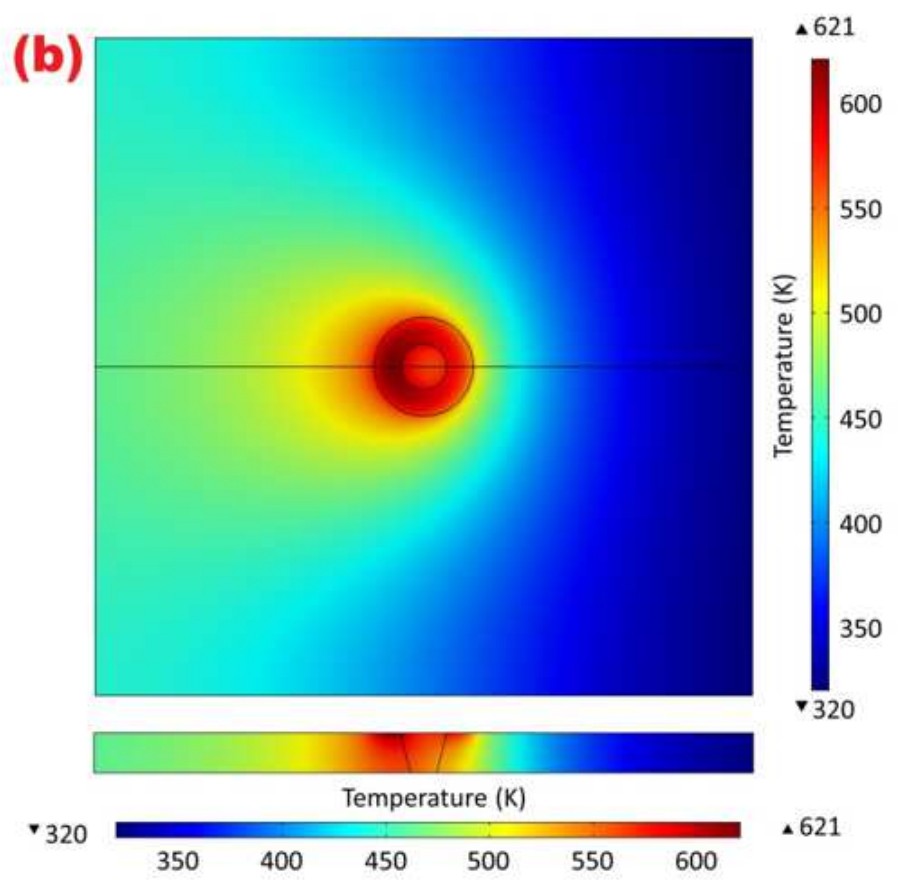

Taper cylindrical pin

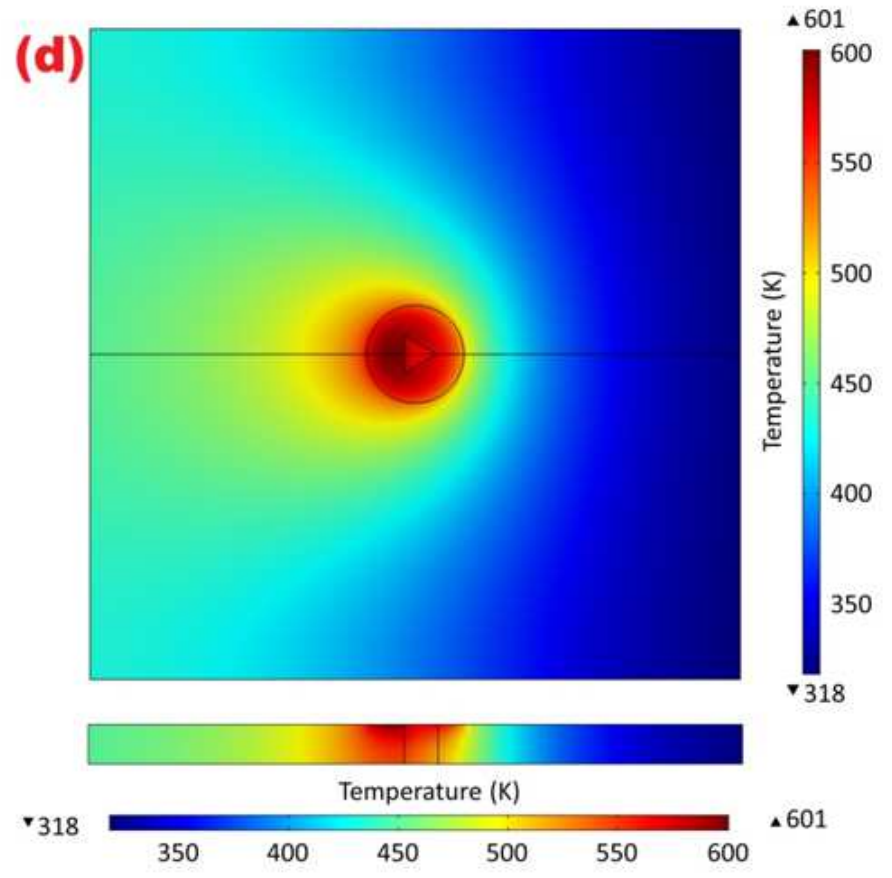

Triangular pin

\section{Figure 8}

Graphical illustration of the generated temperature contour graphs on the top surface of the work piece and on the bonding surfaces for tools with different pin geometries namely (a) Cylindrical Pin (b) Taper Cylindrical Pin (c) Square Pin and (d) Triangular Pin 

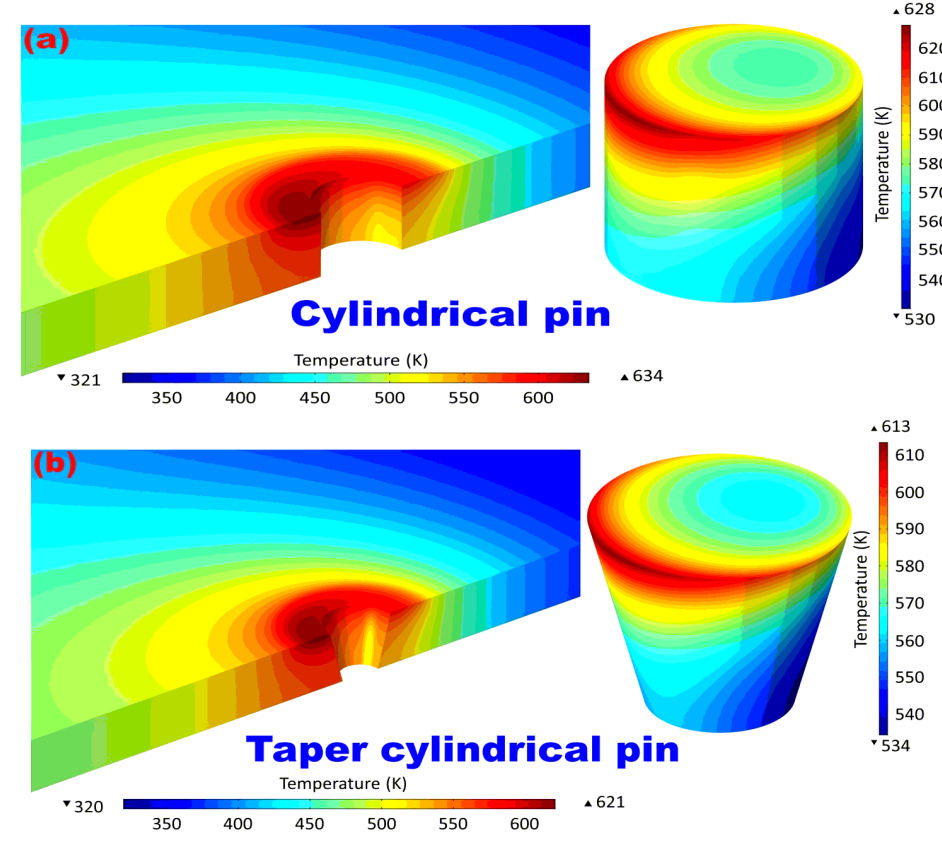
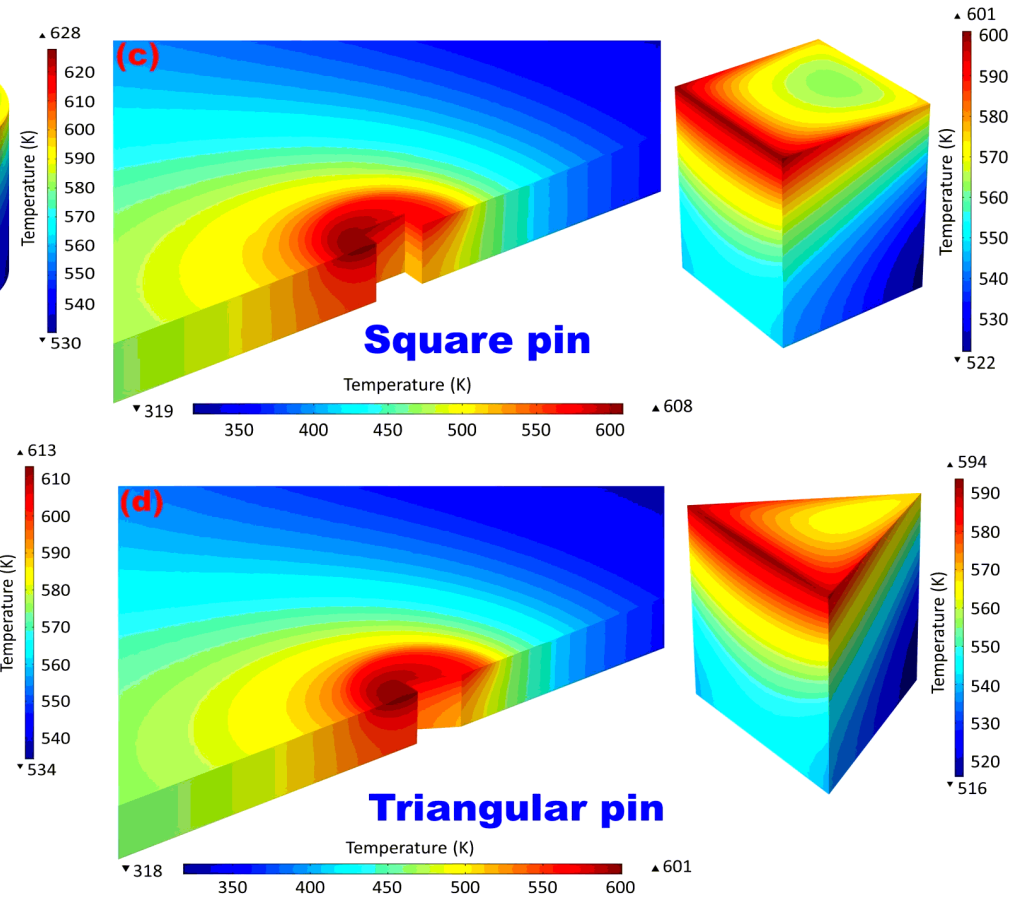

\section{Figure 9}

Graphical illustration of the generated temperature distribution on the tool contact area w.r.t work piece surface and on the different tool pin geometries of the FSW tools including (a) Cylindrical Pin (b) Taper Cylindrical Pin (c) Square Pin and (d) Triangular Pin 

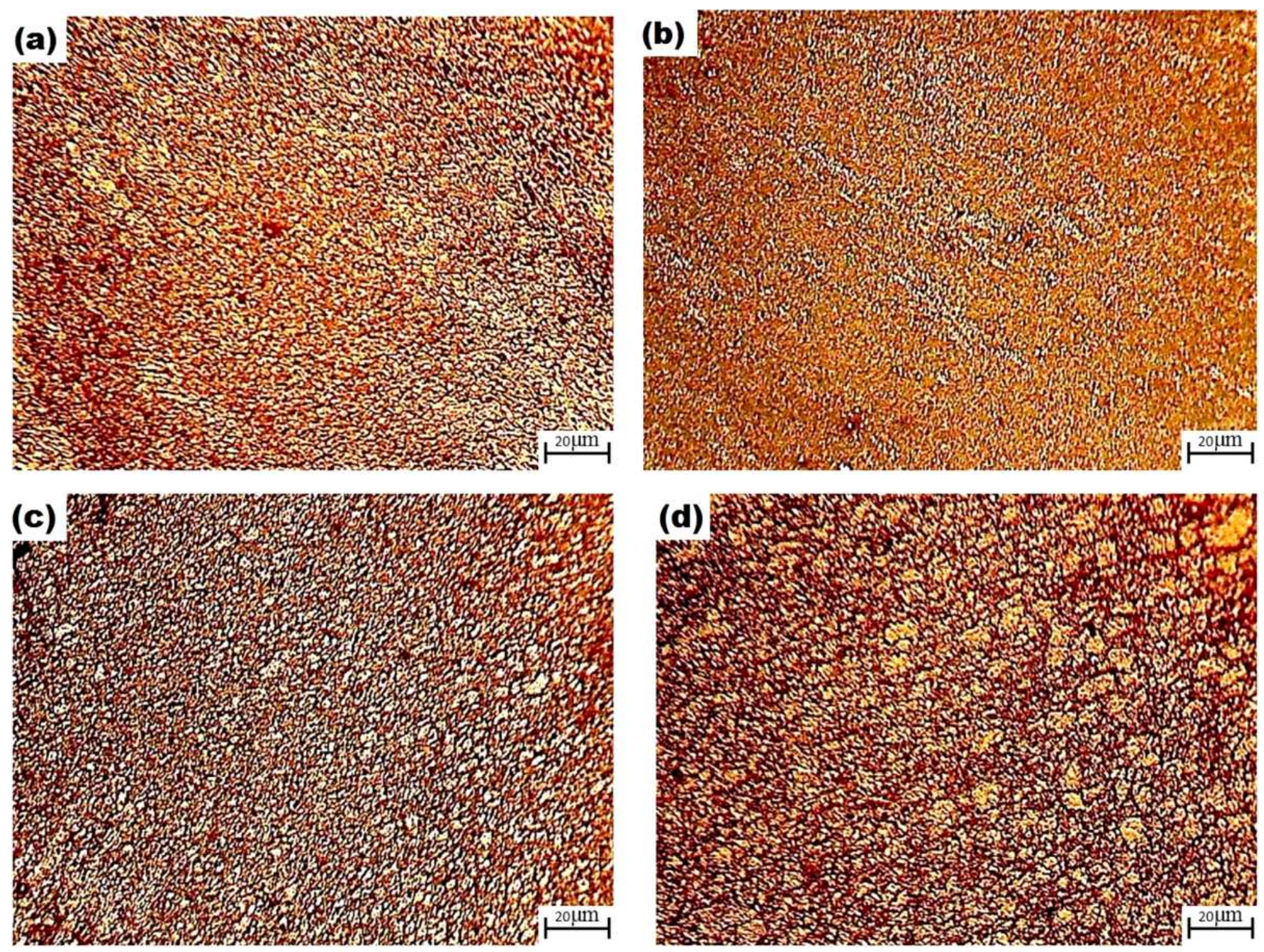

Figure 10

Optical Micrographs of the AZ80A joints fabricated by employing (a) Cylindrical pin geometry (b) Taper Cylindrical pin geometry (c) Square pin geometry and (d) Triangle pin geometry.
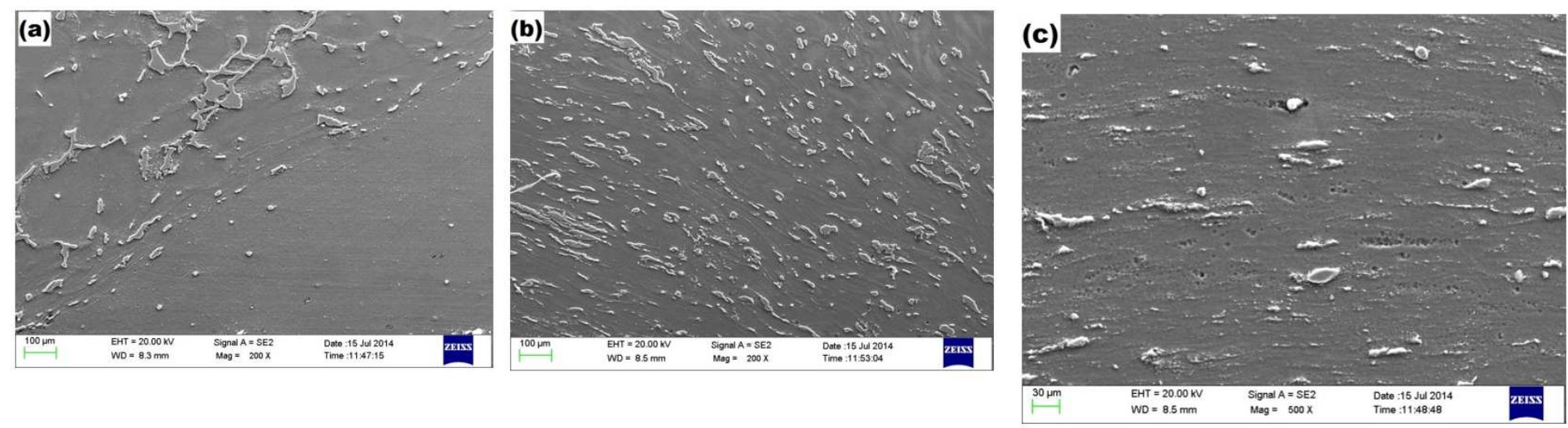

Figure 11 
SEM photographs of the (a) junction of the AZ80A Mg \& the region which are dominated by exhilarating action of rotating shoulder of tool (b) thermo mechanically transformed region and (c) centre of the zone of stir
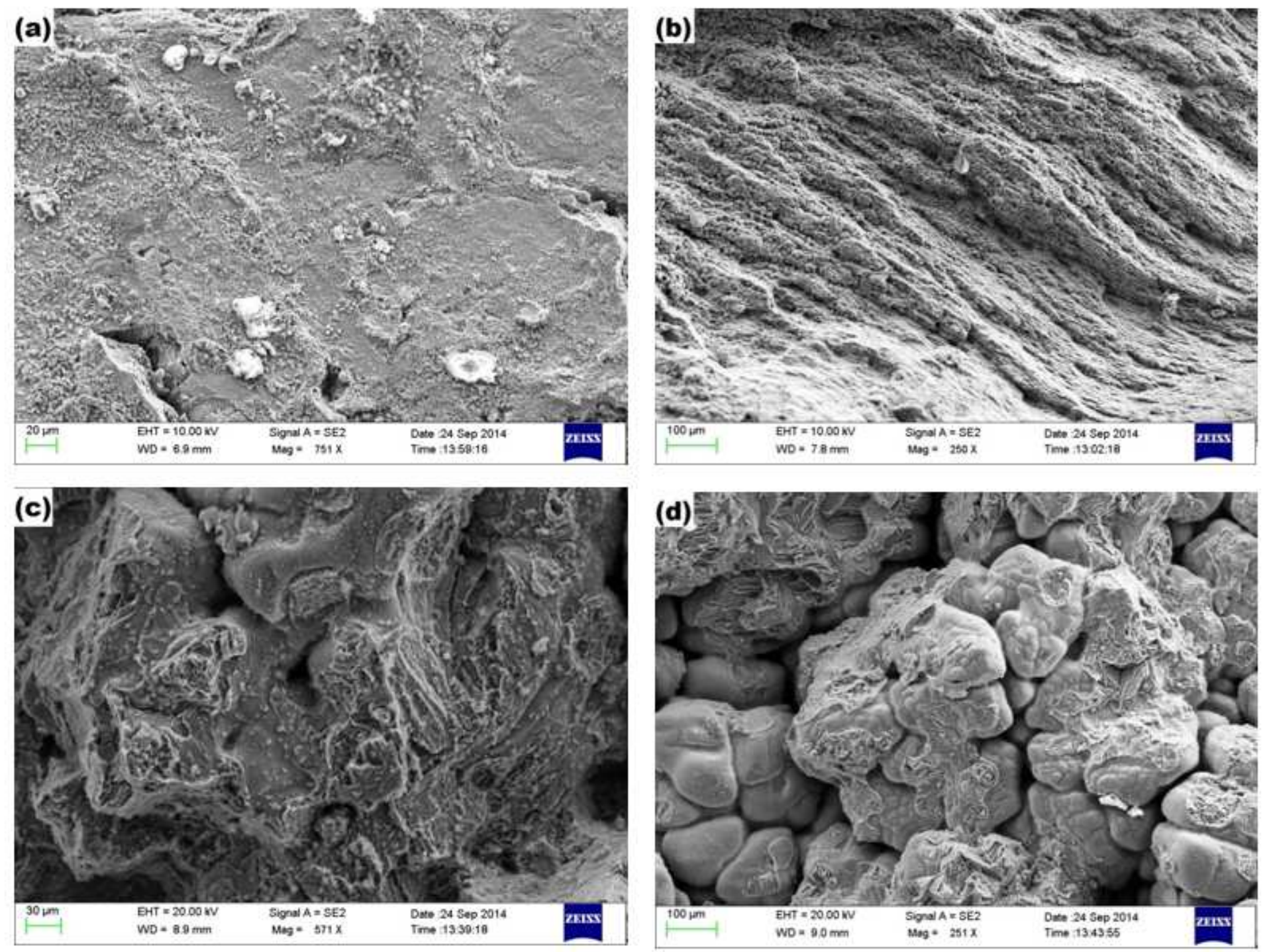

\section{Figure 12}

SEM fractographs of the fractured tensile specimen obtained during the employment of FSW tools with (a) cylindrical (b) taper cylindrical (c) square and (d) triangle pin geometries 